\title{
A Progressive Damage Model of Textile Composites on Meso-Scale using Finite Element Method: Static Damage Analysis
}

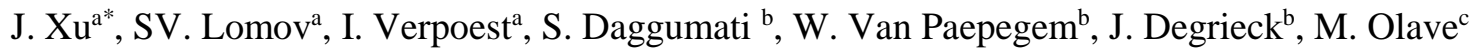

${ }^{a}$ Katholieke Universiteit Leuven, Department of Metallurgy and Materials Engineering, Kasteelpark Arenberg 44 B-3001 Leuven, Belgium

${ }^{\mathrm{b}}$ Ghent University, Dept. of Materials Science and Engineering, Sint-Pietersnieuwstraat 41, 9000 Gent, Belgium

'IK4-IKERLAN, Dept. of Mechanical Engineering, Mondragon, Spain

Email: xujian1028@hotmail.com

\section{SUMMARY}

A meso-scale finite element model for static damage in textile composites was established. The impregnated yarn is taken as homogeneous and transverse isotropic material, whose mechanical properties are calculated using Chamis' equations. The damage modes are determined by using the Tsai-Wu criterion and additional criteria. The Murakami damage tensor is used to calculate the post-damage stiffness matrix. The model has been validated using plain weave and twill weave carbon-epoxy composites. The initiation of inter-fibre matrix crack and fibre rupture was analyzed using this meso-FE model.

Keywords: meso-scale; textile composite; finite elements; damage initiation, fibre rupture, crimp 


\section{INTRODUCTION}

Textile reinforced composites are increasingly applied to automotive, aerospace, wind energy and other high-tech industries. The mechanical properties of the textile composites are highly dependent on the geometry of reinforcements, which are produced with variable parameters and complex architectures. Hence, a reliable numerical method, linking the internal structure to the mechanical characteristics, for instance the modulus, strength, and damage onsets based on given loading conditions, will be of great value.

Devoted to this purpose, earlier studies intended to predict the elastic properties based on a modified laminate theory with analytical approaches ${ }^{1-3}$. Inherent limitations of these approaches are the inflexibility to the geometry variation.

In the past decade, the FE-method has been gaining popularity in modelling the degradation of mechanical properties as well as the damage evolution ${ }^{4-10}$. Zako gave a brief review of the damage analysis for woven composite materials ${ }^{11}$ : the modelling work in ${ }^{12}$ has considered the geometrical non-linearity without the stiffness degradation, or the whole stiffness was reduced to zero (isotropic damage) ${ }^{13}$; the anisotropic damage, correspondent to its damage mode, has been applied in ${ }^{14-18}$, but the reduced components and the reduced value are still questionable, as the knowledge was experimentally based. Zako and coworkers ${ }^{11}$ proposed to use a theoretical anisotropic damage constitutive equation, the Murakami damage tensor ${ }^{19}$, to represent the damage mechanics, which was implemented on the Gaussian point scale of a meso-FE model. Prediction of his model showed reasonable agreement with the test results of glass fibre woven composites. Later on, however, when this model was applied to carbon fibre composites ${ }^{20}$, the static strength and Young's modulus were highly underestimated. 
As a progressive damage model, the present work contains three parts: 1) stress analysis, 2) failure analysis and 3) material degradation. A non-linear numerical approach, employing the anisotropic damage model, has been implemented in ABAQUS® user material (UMAT). As a prerequisite, the geometrical description of the reinforcement of a unit cell [Figure 1 (a)] was drawn with a textile geometry generator ${ }^{21,22}$, meshed using a FE mesher ${ }^{23-25}$ - Figure 1 (b), and transformed afterwards into ABAQUS® software package [Figure 1 (c)].

On top of that, the 'stiffening effect' ${ }^{26,27}$ of carbon fibers has been taken into account and implemented. Despite aggregation of material damage, the global response of carbon fiber composites show quasi-linear or even slightly stiffening behavior, which evidences the existence of carbon fibre stiffening. Without this consideration the global response may hardly be correctly predicted.

Meantime, the interlocking introduced stress concentration is always a concern in textile composite materials. At the location where two yarns meet each other, the material exhibits highly inhomogeneity and anisotropy, and the stress state turns to be intricate. Comparing to uni-directional composites, the stress concentration in textile composites remarkably promotes the damage initiation and reduces the ultimate load. In order to have a clear insight into this phenomenon an exhaustive local stress analysis, about which limited work has been reported, becomes essential.

Therefore, this paper provides a detailed numerical analysis of interlock-introduced stress concentration in weft and warp yarns as well as its effects to damage initiation (section 4.4.2) and fibre rupture (section 4.4.4). Using this model, comparative studies have been carried out among two types of plain weave materials and two types of twill weave materials. 

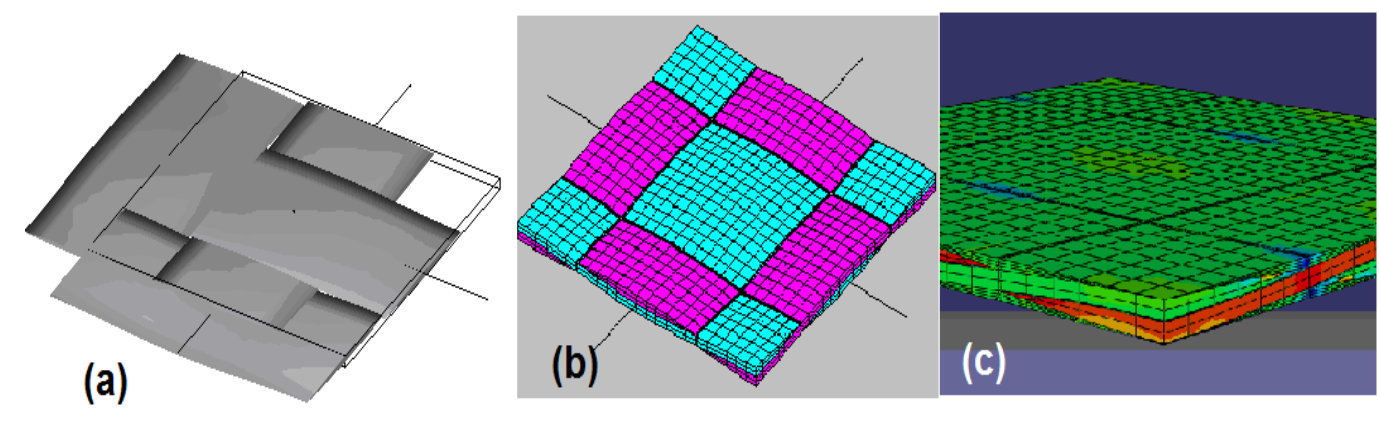

Figure 1: Meso-FE model of textile composites: (a) plain weave geometry by WiseTex ${ }^{22}$, (b) mesh generated by MeshTex, (c) FE model with matrix material in ABAQUS®.

\section{FE-MODEL CONSTRUCTION}

\subsection{Geometrical model}

In WiseTex ${ }^{22}$, the transection of yarns is descripted as an ellipse. Yarn width and thickness in the composite, carefully obtained using microscope, are assigned to the major and minor axes of the transaction. Other parameters of the reinforcement, for instance the dimensions and the fibre volume fraction of a unit cell, are assigned to the geometrical model as well.

With 3D periodic boundary conditions, the single-layered meso-scale model simply represents an internal layer of the textile composite, correlated to the 'periodic shift' in the paper of Ivanov 28. Comparing to other types of intra-ply shift, periodic shift usually predicts an slightly earlier damage initiation. 
(a)

\section{weft}

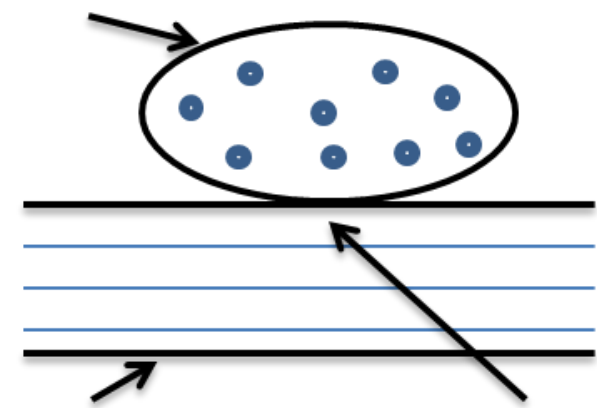

warp (b)

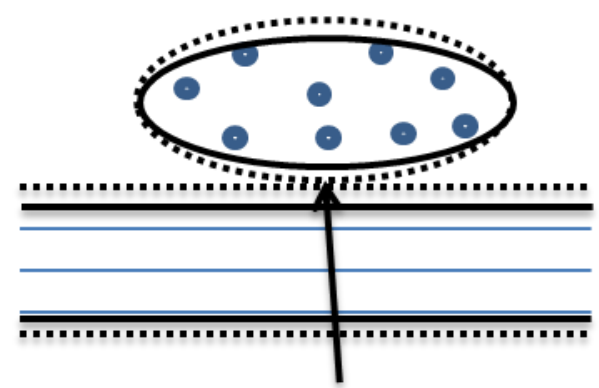

Clearance/Matrix material

Figure 2: The yarn's volume is 'compressed' in order to (1) avoid the contact problem, and (2) insert a thin layer of matrix material.

\subsection{Meshing}

In the next step, the geometry is meshed with MeshTex ${ }^{25,29}$. A very thin layer of elements (matrix material) are inserted between warp and weft yarns at the overlap [Figure 2 (a)(b)]. To remain the thickness of the unit cell unchanged, the yarns have to be 'compressed' - Figure 2 (b). Now two factors have to be born in mind: (1) as the result of compressing, the volume ratio of yarn / unit cell in the FE-model is somehow decreased; (2) however, the fibre volume fraction of the unit cell (total fibre volume) must be kept the same as measured from real composite, since its value dominates the on-axis mechanical behavior. When taking into account these two factors, the fibre volume fraction in the yarns has to be increased somehow.

\subsection{FE model in ABAQUS®}

A MATLAB ${ }^{\circledR}$ script is written to translate the FE model into ABAQUS®, applied with the periodic boundary conditions (based on the translation symmetry of the unit cells ${ }^{9,30,31}$ ). The 'C3D8' elements were used for impregnated yarns and inter-yarn matrix materials. C3D8 element in ABAQUS ${ }^{\circledR}$ means linear hexahedral element with eight integration points. 
The ABAQUS ${ }^{\circledR}$ package is selected because of its excellent performance in material nonlinear calculations and powerful user defined material behavior. Globally, PYTHON® scripts control the program flow, encapsulating all the functionalities such as applying periodic boundary conditions (PBCs), calling user material subroutine (UMAT), calling solver and exchanging data with the database. Locally in each Gaussian point, the user defined material behavior, for instance the static damage initiation and propagation, is programmed in the UMAT with Fortran language.

\subsection{Mechanical properties of the impregnated yarn}

The impregnated yarns are treated as homogeneous and transverse isotropic material. Due to aforementioned nesting effect and yarn compressing (Figure 2), the fibre volume fraction of the impregnated yarns is assigned with an increased value, which is less than $10 \%$ (from $65 \%$ to $74.4 \%$ ). With the increased fibre volume fraction in yarns, the strength components, stiffness components and Poisson's ratios of the impregnated yarns can be calculated through the Chamis' equations ${ }^{9,32-34}$ as follows:

$$
S_{11}^{t}=V_{F} S^{f i b}+\left(1-V_{F}\right) S_{m}^{t} \frac{E_{m}}{E_{11}^{f i b}}
$$

$S_{11}^{c}=\frac{G_{m}}{1-V_{F}\left(1-\frac{G_{m}}{G_{12}^{f b}}\right)}$

$S_{22}^{t}=\left(1-V_{F}\right) S_{m}^{t} \frac{E_{22}}{E_{m}}$

$$
S_{22}^{c}=\left(1-V_{F}\right) S_{m}^{c} \frac{E_{22}}{E_{m}}
$$




$$
\begin{aligned}
& S_{12}=S_{23}=S_{13}=\frac{1}{2} S_{22}^{c} \\
& E_{11}=V_{F} E_{11}^{f i b}+\left(1-V_{F}\right) E_{m} \\
& E_{22}=E_{33}=\frac{E_{m}}{1-\sqrt{V_{F}}}\left(1-\frac{E_{m}}{E_{22}^{f i b}}\right) \\
& G_{12}=G_{13}=\frac{G_{m}}{1-\sqrt{V_{F}}\left(1-\frac{G_{m}}{G_{12}^{f i b}}\right)} \\
& G_{23}=\frac{G_{m}}{1-\sqrt{V_{F}}\left(1-\frac{G_{m}}{G_{23}^{f i b}}\right)} \\
& \mu_{23}=\frac{E_{22}}{2 G_{23}}-1 \\
& \mu_{12}=\mu_{13}=V_{F} \mu_{12}^{f i b}+\left(1-V_{F}\right) \mu_{m}
\end{aligned}
$$

where $V_{F}$ is the adapted yarn fibre volume fraction; $E, G, \mu$ and $S$ are tensile modulus, shear modulus, Poisson's ratio and strength component, respectively. Subscripts ' 1 ', '2' and '3' indicate the longitudinal fibre direction, transverse fibre directions in the material coordinate system. Subscript ' $m$ ' stands for 'matrix' while superscript ' $f i b$ ' stands for 'fibre'. The superscripts ' $t$ ' and ' $c$ ' of strength components designate tension and compression, respectively.

\subsection{Damage modes and stiffness degradation}

Damage in element will be captured by Tsai-Wu criterion ${ }^{35,}{ }^{36}$. The post-damage behavior (stiffness degradation) of a Gaussian point is described by the anisotropic damage model, as 
shown in Figure 3. In this figure, the axis 1, 2 and 3 are correspondent to longitudinal and two transversal directions of the material coordinate system in the fibre bundles; $t$ and $c$ stand for tension and compression. Mode 1 delineates fibre breakage while others are for inter-fibre cracks. The damage mode is activated by the maximum value of the stress-to-strength ratios 9,11 (the second row of Figure 3). The matrix is considered as isotropy with one damage mode, the damage of which is indicated by maximum normal stress criterion.

Tsai-Wu criterion does not provide further information to differentiate the fibre breakage and inter-fibre crack. The distinction between these damage modes is vital important for the anisotropic stiffness degradation model. Additional criteria have been proposed by Zako ${ }^{11}$. As shown in the second row of Figure 3, six terms of stress-strength ratio are used to indicate the damage modes: (a) $\sigma_{1}^{2} / S_{1}^{t} S_{1}^{c}$, (b) $\sigma_{2}^{2} / S_{2}^{t} S_{2}^{c}$, (c) $\tau_{12}^{2} / S_{12}^{2}$, (d) $\sigma_{3}^{2} / S_{3}^{t} S_{3}^{c}$, (e) $\tau_{13}^{2} / S_{13}^{2}$ and (f) $\tau_{23}^{2} / S_{23}^{2}$. When the value of term (a) is the maximum among all of the six terms, the damage is determined as fibre breakage, which links to mode 1 in Figure 3. Likewise, the maximum term is (b) or (c), it links to mode 2, (d) or (e) to mode 3 and (f) to mode 4.

\begin{tabular}{|c|c|c|c|c|c|}
\hline \multirow[b]{2}{*}{ Damage mode } & \multicolumn{4}{|c|}{ Anisotropic damage model for fiber } & \multirow[b]{2}{*}{$\begin{array}{l}\text { Isotropi } \\
\text { damage mode } \\
\text { for matrix }\end{array}$} \\
\hline & Mode 1 & Mode 2 & Mode 3 & & \\
\hline $\begin{array}{c}\text { Maximum } \\
\text { stress-to-strength } \\
\text { ratio } \\
\end{array}$ & $\frac{\sigma_{1}^{2}}{S_{1}^{t} S_{1}^{c}}$ & $\frac{\sigma_{2}{ }^{2}}{S_{2}{ }^{t} S_{2}{ }^{c}}$ or $\left(\frac{\tau_{12}}{S_{12}}\right.$ & $\frac{\sigma_{3}{ }^{2}}{S_{3}{ }^{t} S_{3}{ }^{c}}$ or $\left(\frac{\tau_{13}}{S_{13}}\right.$ & $\left(\frac{\tau_{23}}{S_{23}}\right)^{2}$ & 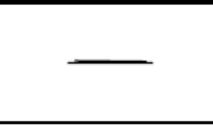 \\
\hline $\begin{array}{l}\text { Damage tensor } \\
{\left[\begin{array}{cccc}D_{1} & 0 & 0 \\
0 & D_{2} & 0 \\
0 & 0 & D_{3}\end{array}\right]}\end{array}$ & {$\left[\begin{array}{lll}1 & 0 & 0 \\
0 & 1 & 0 \\
0 & 0 & 1\end{array}\right]$} & {$\left[\begin{array}{lll}0 & 0 & 0 \\
0 & 1 & 0 \\
0 & 0 & 0\end{array}\right]$} & {$\left[\begin{array}{lll}0 & 0 & 0 \\
0 & 0 & 0 \\
0 & 0 & 1\end{array}\right]$} & {$\left[\begin{array}{lll}0 & 0 & 0 \\
0 & 1 & 0 \\
0 & 0 & 1\end{array}\right]$} & {$\left[\begin{array}{lll}1 & 0 & 0 \\
0 & 1 & 0 \\
0 & 0 & 1\end{array}\right]$} \\
\hline
\end{tabular}

Figure 3: Damage modes and the corresponding damage tensor ${ }^{11} . D_{1}, D_{2}$ and $D_{3}$ are principle values of damage tensor, whose application is shown in Equations (13) and (14).

The post-damage stiffness matrix $Q^{*}$ expresses the generalized Hook's law for the damaged material: 
$\left\{\sigma_{j}\right\}=\left[Q_{i j}^{*}\right]\left\{\varepsilon_{i}\right\}$

Referring to ${ }^{9,11}$, the components of $Q^{*}$ are computed based on the initial stiffness matrix $Q$ and the Murakami damage tensor $D$ according to the identified damage mode given in Figure 3, as follows:

$$
\left\{\begin{array}{c}
\sigma_{1} \\
\sigma_{2} \\
\sigma_{3} \\
\tau_{23} \\
\tau_{31} \\
\tau_{12}
\end{array}\right\}=\left[\begin{array}{cccccc}
d_{1}^{2} Q_{11} & d_{1} d_{2} Q_{12} & d_{1} d_{3} Q_{13} & 0 & 0 & 0 \\
& d_{2}^{2} Q_{22} & d_{2} d_{3} Q_{23} & 0 & 0 & 0 \\
& & d_{3}^{2} Q_{33} & 0 & 0 & 0 \\
& & & d_{23} Q_{44} & 0 & 0 \\
& & & & d_{31} Q_{55} & 0 \\
\gamma_{23} \\
\gamma_{31} \\
\gamma_{12}
\end{array}\right\}
$$

where

$$
\left\{\begin{array}{c}
d_{1}=1-D_{1}, \quad d_{2}=1-D_{2}, \quad d_{3}=1-D_{3} \\
d_{23}=\left(\frac{2 d_{2} d_{3}}{d_{2}+d_{3}}\right)^{2}, d_{31}=\left(\frac{2 d_{3} d_{1}}{d_{3}+d_{1}}\right)^{2}, d_{12}=\left(\frac{2 d_{1} d_{2}}{d_{1}+d_{2}}\right)^{2}
\end{array}\right.
$$

The principle values $D_{1}, D_{2}$ and $D_{3}$ are zero for a virgin material and set to 0.99 after damage occurrence while the value of 1.0 will introduce numerical singularity ${ }^{11}$.

Gorbatikh ${ }^{37}$ has exammed the applicability of Murakami model on textile composites. She reveals that the CDM based model has difficulties in predict the direction of the crack evolution when the considered volume is shear dominated (external shear loading to a unit cell). In contrast, CDM based model is, however, adequate to be used in tension dominated volume.

\subsection{Road map}


Figure 4 shows the road map of the static damage modelling of textile composites. As aforementioned, the geometry of the reinforcement is meshed and the elements inside the yarn volume are assigned with the calculated mechanical properties using empirical equations [Equations (1)-(11)]. The macro-level loading applied to a sample is transformed to periodic boundary conditions on a unit cell ${ }^{9}$.

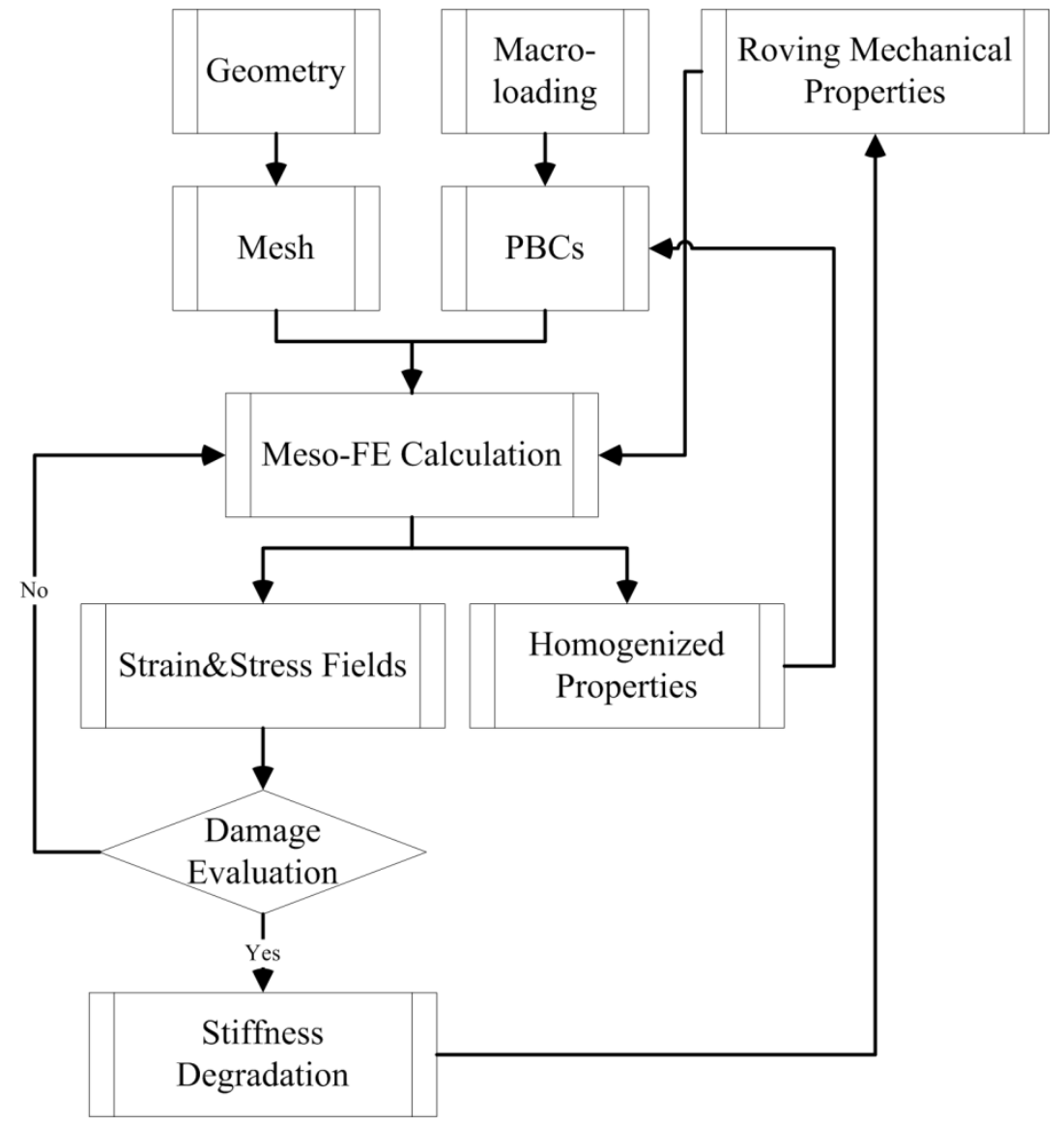

Figure 4: The road map for static damage modelling of textile composites.

With the mesh, material properties and boundary conditions, the meso-FE-model is established. By solving the model, the strain and stress distribution in the unit cell are obtained. These strain and stress fields are used further serving for two purposes: (1) identifying local damage by using Tsai-Wu or maximum normal stress failure criterion, and (2) evaluating the averaged stiffness of the unit cell by using homogenization technique. 
The damage mode can be determined using the additional criteria in the last section: (1) for fibre rupture (critical failure state), all of the stiffness components are set to very small values (zero values lead to numerical singularity) (2) for inter-fibre matrix failure, only the related stiffness component(s) are reduced to small value(s) (subcritical failure). The degraded stiffness is evaluated based on Murakami damage tensor - Figure 3. In the next loading step, the degraded stiffness is reassigned to the deteriorated elements for the next calculation until the final failure of the unit cell. Under tension loading along the fibre direction, the final failure can be determined when the first fibre rupture is detected. Hence, the correspondent numerical tensile stress applied on the unit cell is taken as the predicted strength.

\section{VALIDATION USING DATA FROM LITERATURE}

\subsection{Material}

To validate the proposed algorithm, the experimental data of two types of textile reinforced carbon fibre epoxy composites ${ }^{38}$, plain weave $12 \mathrm{~K}$ tow laminate (PW12K) and plain weave $3 \mathrm{~K}$ tow laminate (PW3K), are utilized. The composite materials studied in ${ }^{38}$ are produced with the same fibre/resin system (details not given), aiming at disclosing the influence of the reinforcement structures, for example the weave crimp and yarn thickness, to mechanical behavior.

\subsection{Input data}

Despite the unreported specifications of the fibre/resin system, the properties of the fibres can be estimated by evaluating the static mechanical properties of the two composite materials. The mechanical properties of the composites in the fibre direction are strongly dependent on the properties of carbon fibres, which of literature ${ }^{38}$ tends to be a medium modulus carbon fibre with high strength; the values used in the model are listed in Table 1.E, G, S and $\mu$ are tensile modulus, shear modulus, tensile strength and Poisson's ratio of the fibres, respectively. 
For the epoxy-matrix material, a typical value of $2.75 \mathrm{GPa}^{39}$ is used for the Young's modulus and 0.4 for the Poisson's ratio.

Table 1: Fibre mechanical properties as input for calculation ${ }^{40}$

\begin{tabular}{l|ccccc|cc}
\hline \hline Properties & $E_{11}$ & $E_{22}$ & $G_{12}$ & $G_{23}$ & $S_{1}^{t}$ & $\mu_{12}$ & $\mu_{23}$ \\
& \multicolumn{7}{|c}{$(\mathrm{GPa})$} \\
& 238 & 20 & 20 & 24 & 3.5 & 0.23 & 0.3 \\
\hline Input & & & & & & & \\
\hline
\end{tabular}

Figure 5 exhibits the meso-FE meshes of the reinforcements of PW12K and PW3K. The model of PW12K has double-sized dimensions compared to PW3K and a slightly higher crimp. The geometrical parameters of the reinforcements are listed in Table 2.

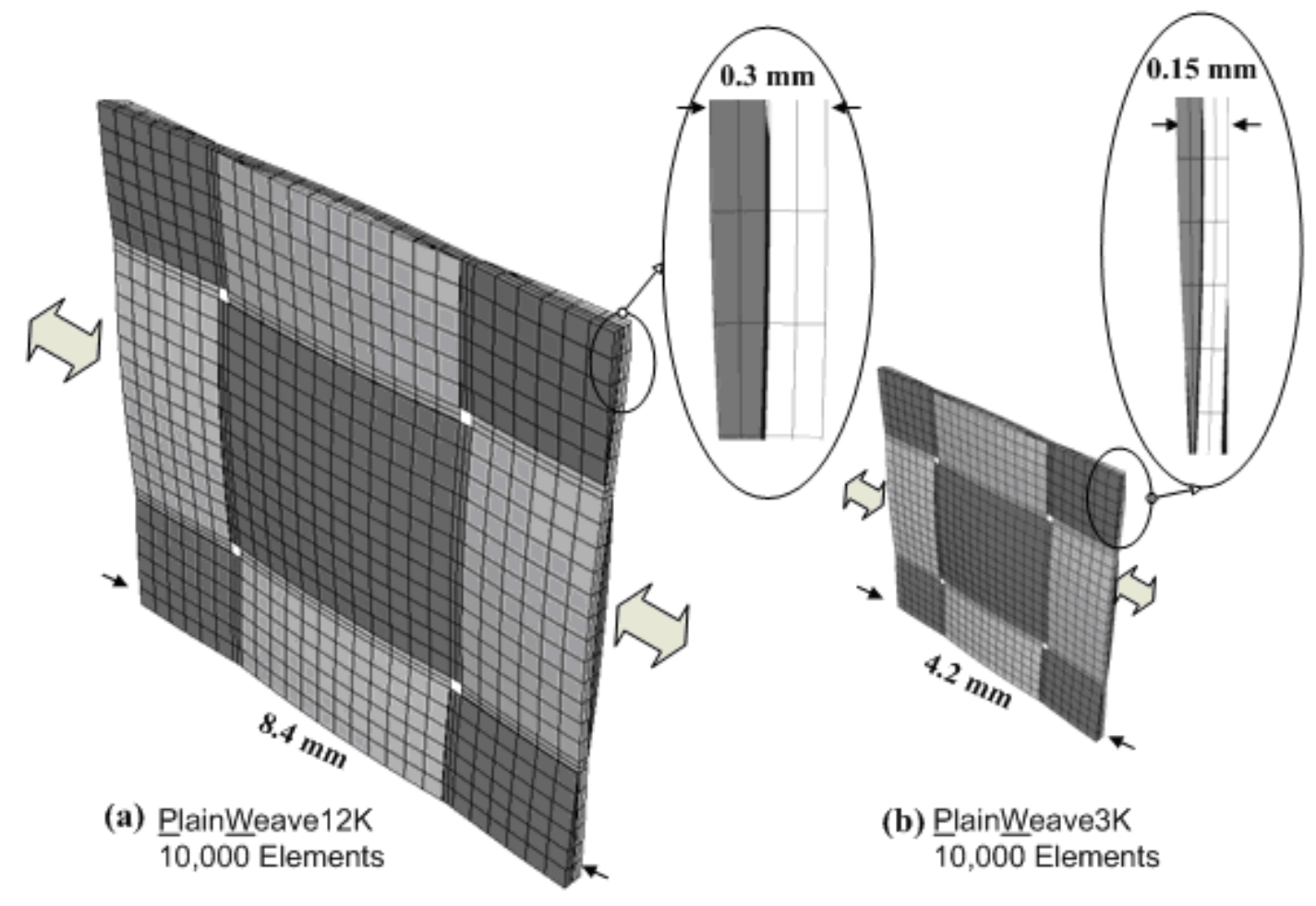

Figure 5: The meso-FE models of the reinforcements for two types of plain weave carbon/epoxy composites: (a) PW12K and (b) PW3K 
Table 2: The geometrical parameters of reinforcements for plain weave carbon/epoxy composites PW3K and PW12K

\begin{tabular}{lccc}
\hline \hline Specimen & & PW3K & PW12K \\
\hline Total $V_{f}$ & $(\%)$ & & 50.4 \\
Yarn width & $(\mathrm{mm})$ & 2 & 4 \\
Yarn thickness & $(\mathrm{mm})$ & 0.075 & 0.150 \\
Crimp & $(\%)$ & 0.90 & 0.92 \\
\hline
\end{tabular}

The yarn mechanical properties are calculated using Equation (1)-(11) with an increased yarn fibre volume fraction $V_{y, F}=74.4 \%, 9.4 \%$ higher than the average value in the test samples. The overall fibre volume fraction of the models in Figure 5 is $50.4 \%$, the same as that in the test. The calculated yarn properties are listed in Table 3 .

Table 3 Calculated yarn mechanical properties in textile composites: $V_{y, F}=\mathbf{7 4 . 4 \%}$

\begin{tabular}{l|cccc|ccccc}
\hline \hline Properties & $E_{11}$ & $E_{22}$ & $G_{12}$ & $G_{23}$ & $S_{1}^{t}$ & $S_{1}^{c}$ & $S_{2}^{t}$ & $S_{2}^{c}$ & $S_{12}$ \\
& \multicolumn{3}{|c|}{$(\mathrm{GPa})$} & & \multicolumn{7}{c}{$(\mathrm{MPa})$} \\
& 117.8 & 10.7 & 5.4 & 5.6 & 2604.0 & 3336 & 76.2 & 118.1 & 59 \\
\hline Values & & & & & & & & & \\
\hline
\end{tabular}

\subsection{Validation}

The calculated mechanical properties are compared to the experimental data ${ }^{38}$ in Table 4 . The calculated longitudinal moduli, tensile strengths and ultimate strain show good agreements to the experiment. 
Table 4: Material properties of plain weave carbon/epoxy: experiment ${ }^{38}$ versus FE-calculation

\begin{tabular}{lccccc}
\hline \hline & & Total $V_{f}$ & Young's modulus & Tensile strength & Ultimate strain \\
& & $(\%)$ & $(\mathrm{GPa})$ & $(\mathrm{MPa})$ & $(\%)$ \\
\hline \multirow{2}{*}{ PW12K } & Exp. & 61 & 807 & 1.30 \\
& FEM & 50.4 & 64 & 858 & 1.24 \\
& EW3K & & 71 & 820 & 1.20 \\
& FEM & & 66 & 853 & 1.22 \\
\hline
\end{tabular}

For textile composites, the modulus during tensile test shows nonlinearity. One reason for it could be the stiffening of carbon fibres. In ${ }^{26,27}$, it is reported that the carbon fibres exhibit stiffening during tension, termed 'strain stiffening' ${ }^{41}$ : for the high strength and medium modulus fibres, a $20 \%$ increase of longitudinal modulus is reported at a tensile strain of $1 \%$. Another reason could be the reduction of the waviness in stretch. Therefore, the modulus of the textile composites should be provided with the strain range where it was taken.

However, for PW3K and PW12K in ${ }^{38}$ the strain ranges were not given. Hence the FEM predicted moduli in this table are the average from strain range $0-0.8 \%$. For PW12K, the modulus is $60.6-67.1 \mathrm{GPa}$ and averaged at $64 \mathrm{GPa}$. For PW3K, the modulus ranged from 63.1 to 69.6 GPa and averaged at $66 \mathrm{GPa}$.

\subsection{Mesh sensitivity}

The MeshTex provides possible choices for element size. In the width direction of an impregnated yarn, 4, 8, 12, 16 or 20 ... elements can be assigned, while in the thickness direction this number is fixed to 4 . In Figure 5 the former number is 12 and the latter is 4 . Usually the finer the mesh is, the more accurate the calculation is. However, a balance has to be met between the accuracy and the efficiency. 
In Figure 6, the mesh sensitivity for PW3K is investigated through the dependence of the longitudinal modulus, strength, and damage onset correlated strain to the mesh size. The modulus varies in a narrow range. It decreases from $66.9 \mathrm{GPa}$ to $65.9 \mathrm{GPa}$ when the number of elements through the width direction of the yarn increases from 4 to 20 . Generally, the modulus can be considered as convergent (The relative error is $0.5 \%$.) when the through-width element number is $8(66.2 \mathrm{GPa})$ compared to the modulus when the through-width element number is 20 (65.9 GPa). The strength reduces from $914 \mathrm{MPa}$ to $852 \mathrm{MPa}$ when the through-width element number increases from 4 to 20 . The relative error between number 8 and number 20 is $1.4 \%$. For damage onset the relative error between the two through-width element numbers is $10 \%$ and the absolute error is $0.05 \%$, which still falls into an acceptable range.

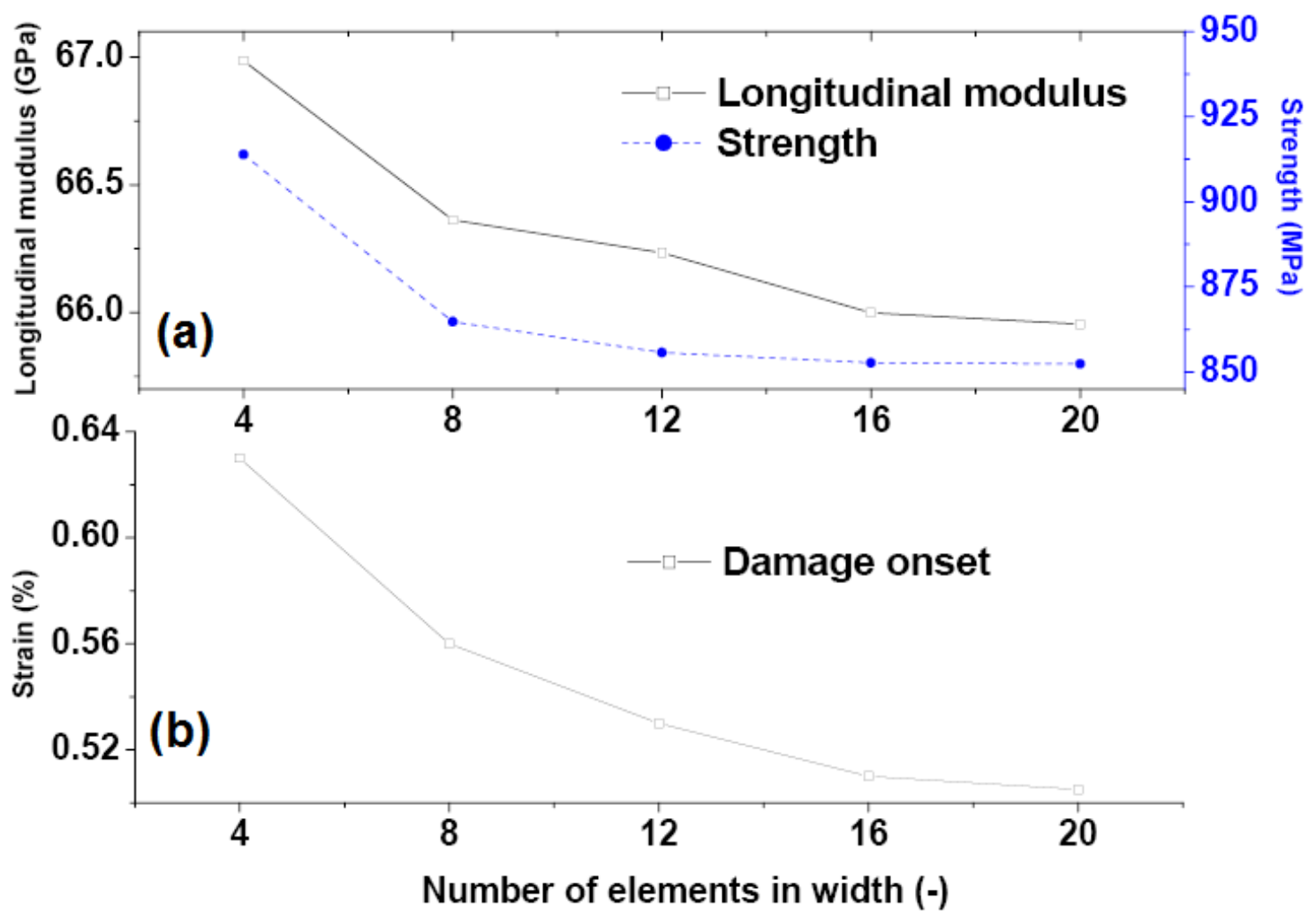

Figure 6: The dependence of longitudinal modulus, strength and damage onset on the mesh size:

(a) longitudinal modulus and predicted strength, and (b) predicted damage onset. 


\section{VALIDATION USING EXPERIMENTAL DATA}

In this section, two types of twill-weave carbon/epoxy composites, woven with $3 \mathrm{~K}$ yarn (CET3K) and 12K yarn (CET12K), and impregnated with the same resin system, have been experimentally investigated. The apparent properties are compared to those from FE calculation. The established FE model is then used to analyze the damage in the weft yarns (damage onset) and in the warp yarns (final failure). Furthermore, a comparative study on crimp-introduced stress concentration is carried out for CET3K and CET12K using the FE model.

\subsection{Material preparation}
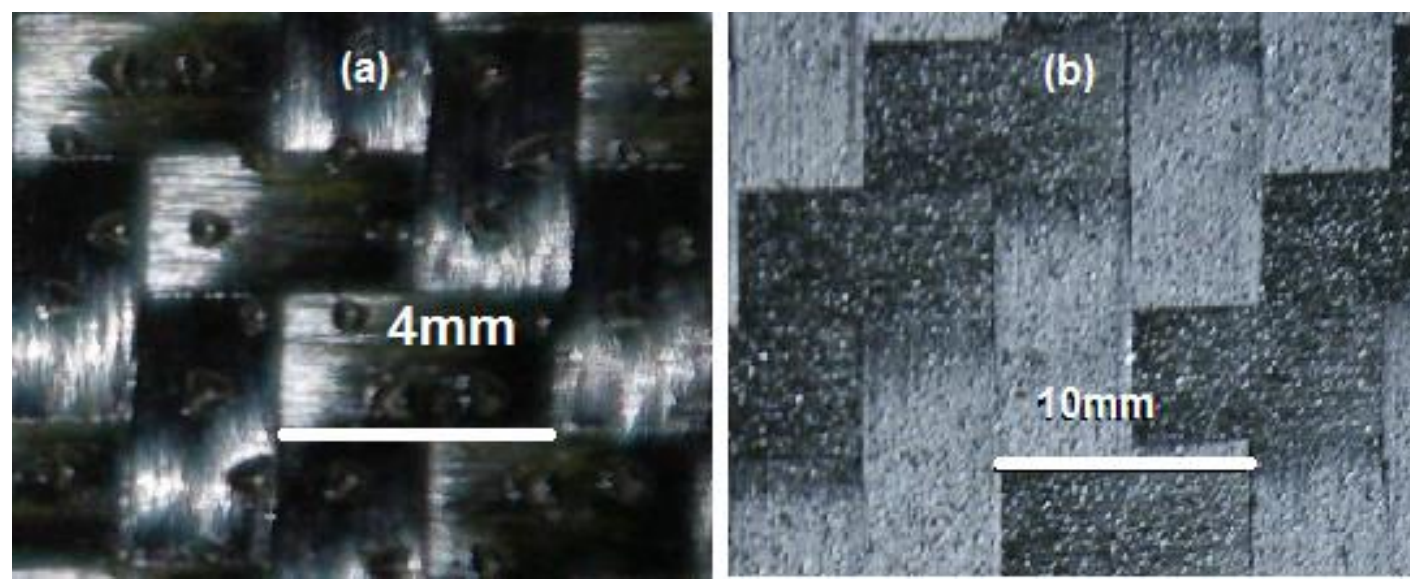

Figure 7: M10.1/T700S prepregs of twill weave $2 / 2$ containing $42 \%$ weigh of resin: (a) $3 \mathrm{~K}$ tow; (b) $12 \mathrm{~K}$ tow.

Two prepreg products, having the same fibre/resin system (M10.1/T700S), are shown in Figure 7. The M10.1 resin ( $42 \%$ of the weight) was impregnated into $3 \mathrm{~K}$ and $12 \mathrm{~K}$ T700S carbon fibre twill weave fabrics, respectively. The $12 \mathrm{~K}$ fabric has a yarn width about $5 \mathrm{~mm}$, wider than that of $3 \mathrm{~K}$ fabric $(2 \mathrm{~mm})$. Table 5 lists the properties of T700S, which will be used to establish the meso-FE model. Besides the given fibre data in Table 5, other fibre data and matrix data are used the same as in section 3 . 
Table 5: Properties of carbon fibre T700S [www.toraycfa.com]

\begin{tabular}{lc}
\hline Tensile strength & $4.9 \mathrm{GPa}$ \\
Tensile modulus & $230 \mathrm{GPa}$ \\
Ultimate strain & $2.1 \%$ \\
Density & $1.8 \mathrm{~g} / \mathrm{cm}^{3}$ \\
Filament diameter & $7 \mu \mathrm{m}$ \\
\hline
\end{tabular}

Thirteen layers of $3 \mathrm{~K}$ prepregs and nine layers of $12 \mathrm{~K}$ prepregs are laid up by hand, respectively. The warp direction of all layers was aligned to the loading direction. According to the Hexcel datasheet, they are processed using a pressurized autoclave to produce $300 \times 300 \times 2.5 \mathrm{~mm}$ plates.

Following ASTM D3039, the parallel-sided specimens $(25 \mathrm{~mm} \times 250 \mathrm{~mm})$ were cut out from the plates using a water-cooled diamond saw. The tapered end-taps are made of fiberglass/epoxy composite plates, and measure $55 \times 25 \times 2 \mathrm{~mm}$. The dimensions of the specimen are shown in Figure 8 .

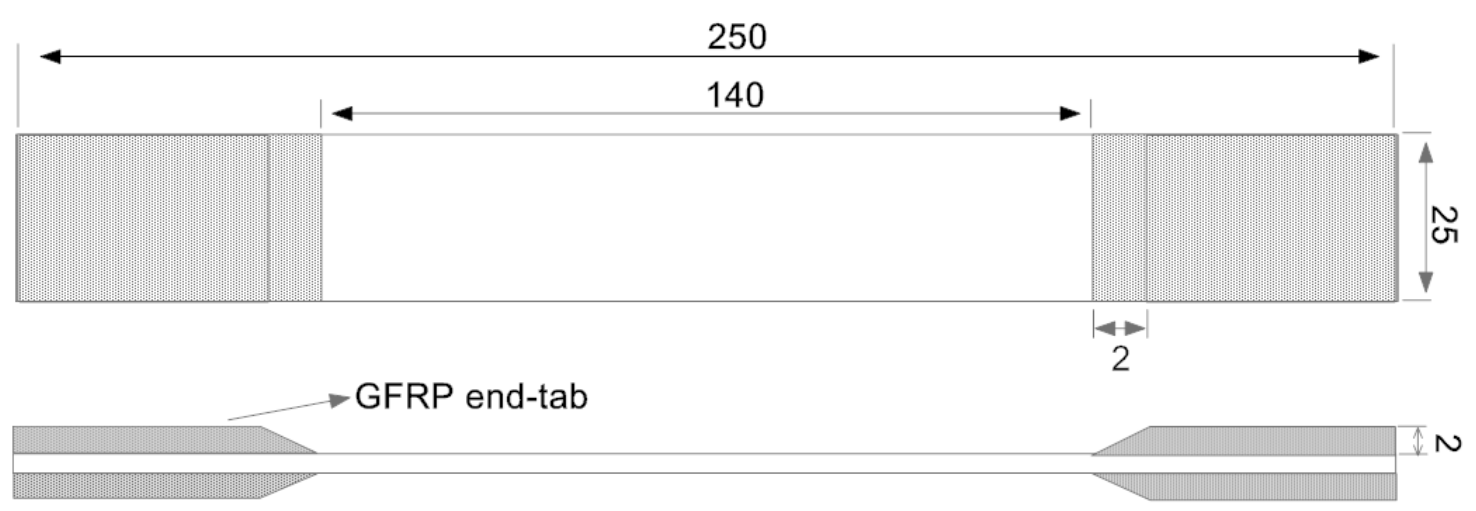

Figure 8: Geometry and dimensions of the specimens (mm)

\subsection{Geometrical parameter characterization}


Using a microscope, the yarn fibre volume fractions of these two materials are measured at 20 locations on the polished transverse sections - Figure 9. The average value for CET3K is $56.7 \%$ $\pm 3.1 \%$, which is slightly lower than that of CET $12 \mathrm{~K}$ at $61.5 \% \pm 2.0 \%$.
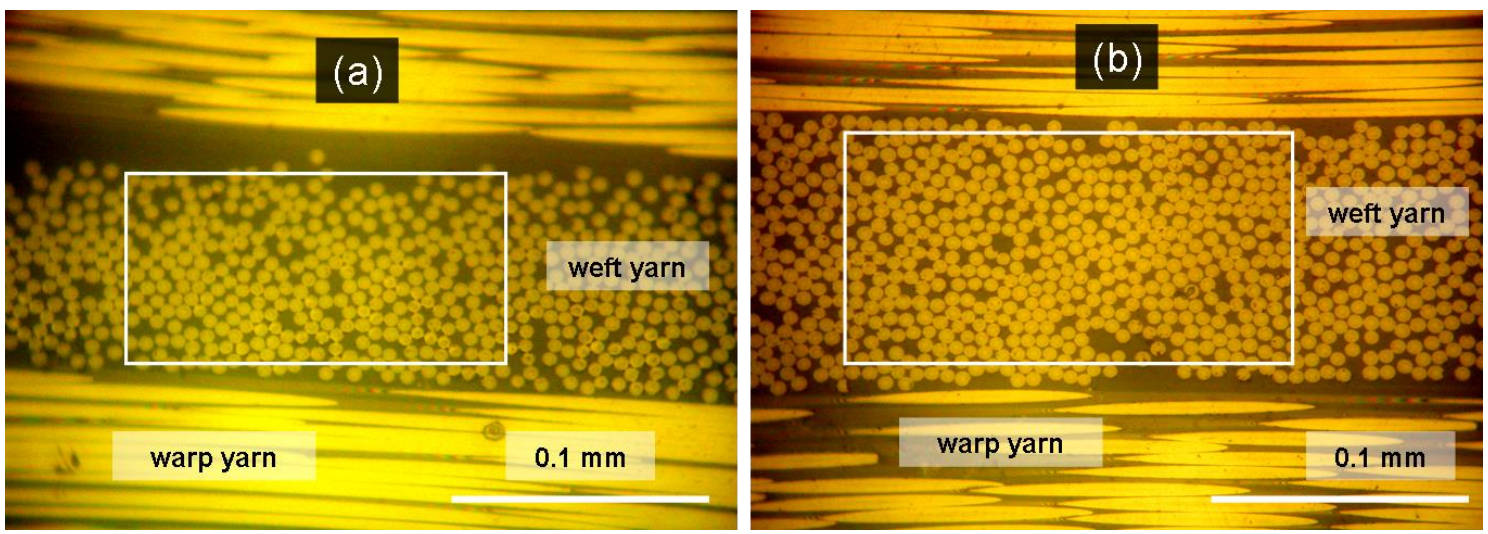

Figure 9: Transverse section micrographs of CET3K and CET12K: (a) CET3K, (b) CET12K.

Apart from the yarn fibre volume fraction, the geometrical parameters of these two materials are characterized and compared in Table 6. CET3K has a higher crimp than CET12K, which will considerably reduce the strength of the composite in the fibre direction. In the modelling part, these geometry parameters are utilized to retrieve the geometrical models of a unit cell.

Table 6: Measured geometrical parameters of the reinforcements of CET3K and CET12K

\begin{tabular}{lcccccc}
\hline \hline Material & Fibre in yarn & Yarn width & Yarn thickness & Ends/Picks & Crimp & Yarn $V_{f}$ \\
& & $(\mathrm{~mm})$ & $(\mathrm{mm})$ & $(1 / \mathrm{cm})$ & $(\%)$ & $(\%)$ \\
\hline CET3K & $3 \mathrm{~K}$ & 2.00 & 0.11 & 4.81 & 0.85 & $56.7 \pm 3.1$ \\
CET12K & $12 \mathrm{~K}$ & 5.46 & 0.16 & 1.82 & 0.28 & $61.5 \pm 2.0$
\end{tabular}

With the adapted yarn $V_{f}$ in Table 7, the strength components and stiffness components of the impregnated yarns are calculated using the Chamis' equations [Equations (1)-(11)] and listed in Table 8. 
Table 7: Geometrical parameters of the reinforcements of CET3K and CET12K in FE model

\begin{tabular}{lcccc}
\hline \hline Material & Yarn width & Yarn thickness & Ends/Picks & Yarn $V_{f}$ \\
& $(\mathrm{~mm})$ & $(\mathrm{mm})$ & $(1 / \mathrm{cm})$ & $(\%)$ \\
\hline CET3K & 2.00 & 0.10 & 4.81 & 67.2 \\
CET12K & 5.46 & 0.15 & 1.82 & 71.4 \\
\hline
\end{tabular}

Table 8: Calculated yarn mechanical properties of CET3K and CET12K using the adapted yarn $V_{f}$ in the FE-models.

\begin{tabular}{|c|c|c|c|c|c|c|c|c|c|c|}
\hline & $E_{11}$ & $\begin{array}{l}E_{22} \\
(\mathrm{GPa}\end{array}$ & $G_{12}$ & $G_{23}$ & $S_{1}^{t}$ & $S_{1}^{c}$ & $\begin{array}{r}S_{2}^{t} \\
(1\end{array}$ & $\begin{array}{r}S_{2}^{c} \\
\mathrm{~Pa})\end{array}$ & $S_{12}$ & $S_{23}$ \\
\hline CET3K & 154.3 & 10.4 & 4.6 & 4.5 & 3265 & 2737 & 66 & 102 & 60 & 60 \\
\hline CET12K & 165.0 & 11.5 & 5.3 & 5.1 & 3500 & 3136 & 67 & 104 & 61 & 61 \\
\hline
\end{tabular}

In order to maintain the global fibre volume fraction in the model the same as in the test samples, the local fibre volume fraction has to be increased - Figure 2. According to Chamis' equation the transverse strength of the yarn is insensitive with a local fiber volume fraction in the range between $55 \%$ and $75 \%$. For example the transverse strengths of CET3K and CET12K both have relative reductions about $4 \%$.

\subsection{Tensile test}

The tensile tests are performed on an Instron 4505 at a cross-head speed of $1 \mathrm{~mm} / \mathrm{min}$. Two acoustic emission (AE) sensors are bound on the two ends of the specimen adjacent to the end-tabs - Figure 10 . The signals generated at a position between two sensors will be analyzed, while the sound events from the griping area will be filtered out. 
The actual surface strains on the specimens are measured by a digital image correlation system.

Specimens, sprayed with white-black speckles, are pictured by a camera. In the post-processing, a sequence of pictures with the continuous slight changes of the relative positions of the speckles are identified and evaluated by $\mathrm{Vic} 2 \mathrm{D} \AA$ to build up the strain contours all along the tensile specimen.

The average strain of the whole specimen, up to the final failure, can be calculated by averaging the local superficial strain in the interested area. Figure 10 shows a specimen mounted in the tensile machine with the AE senor attached and the strain mapping camera setup.

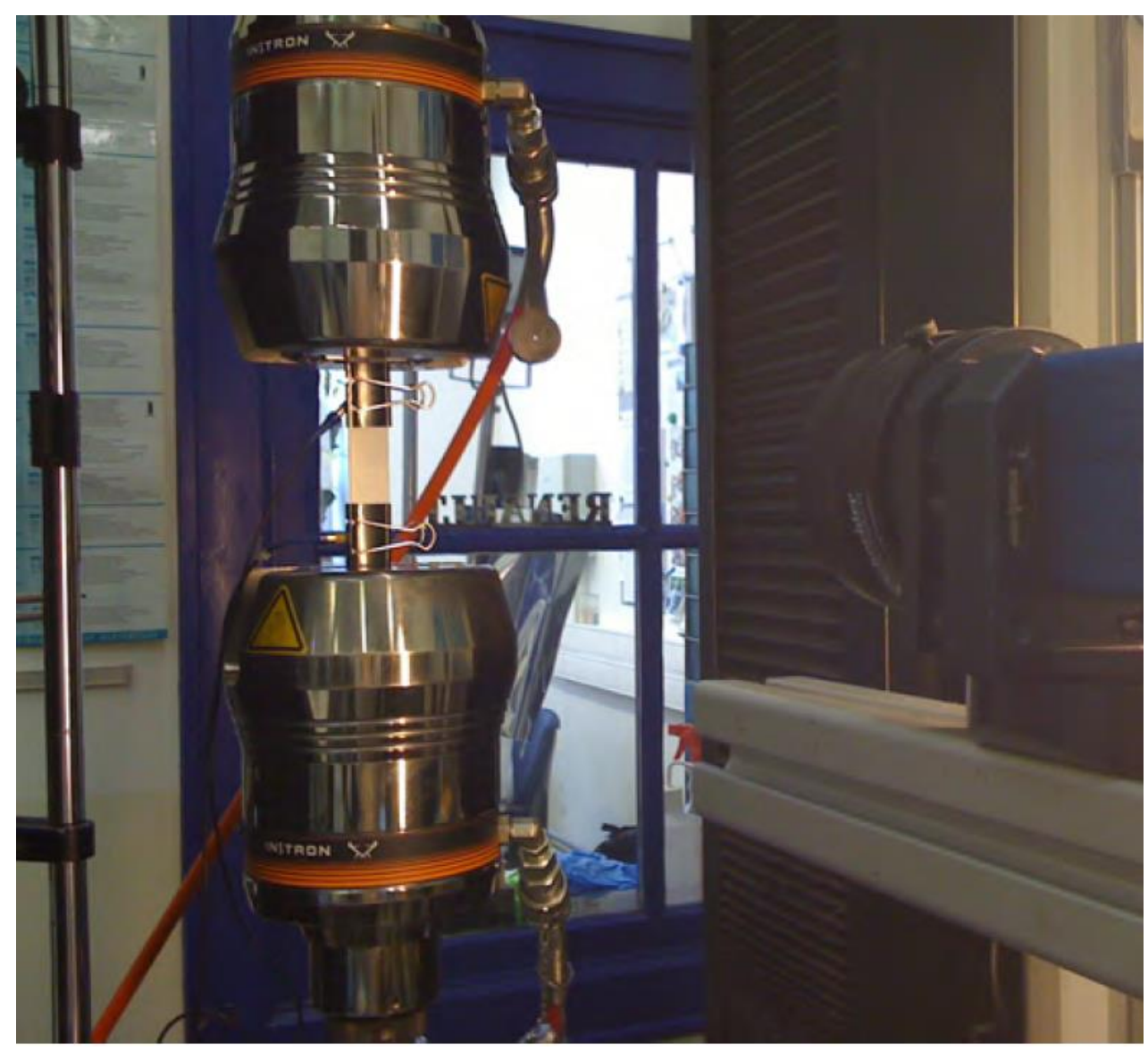

Figure 10: Tensile test with the assistance of acoustic emission (AE) and strain mapping.

By analyzing the data of strain mapping and $\mathrm{AE}$, the specific strain $\varepsilon^{\text {crit }}$, indicating a sudden occurrence of high density of acoustic events, can be determined through the plot of acoustic 
cumulative energy vs strain, - Figure 12 . This specific strain value can be correlated to the damage initiation ${ }^{42-45}$.

\subsection{Validation of apparent properties and damage analysis using FE model}

\subsubsection{Young's modulus}

The Young's moduli of CET3K and CET12K in the warp direction vs. the strain are floating averaged and plotted in Figure 11. The second order trend lines of the data points show the tendency of moduli change during the tensile test: although having big standard deviations, the averaged moduli are neither constant nor monotonic. The averaged modulus of CET3K is about $65 \mathrm{GPa}$ at the beginning of the tension and elevates to the maxima value of $67.5 \mathrm{GPa}$ at the strain of $0.75 \%$. After this, the modulus gradually reduces until to the final failure at the strain of 1.45\%. The similar phenomenon is visualized for CET12K: modulus reaches maximum $66 \mathrm{GPa}$ at $0.9 \%$ of strain and, thereafter, slowly decreases to $59 \mathrm{GPa}$ at the ultimate strain $1.8 \%$. 


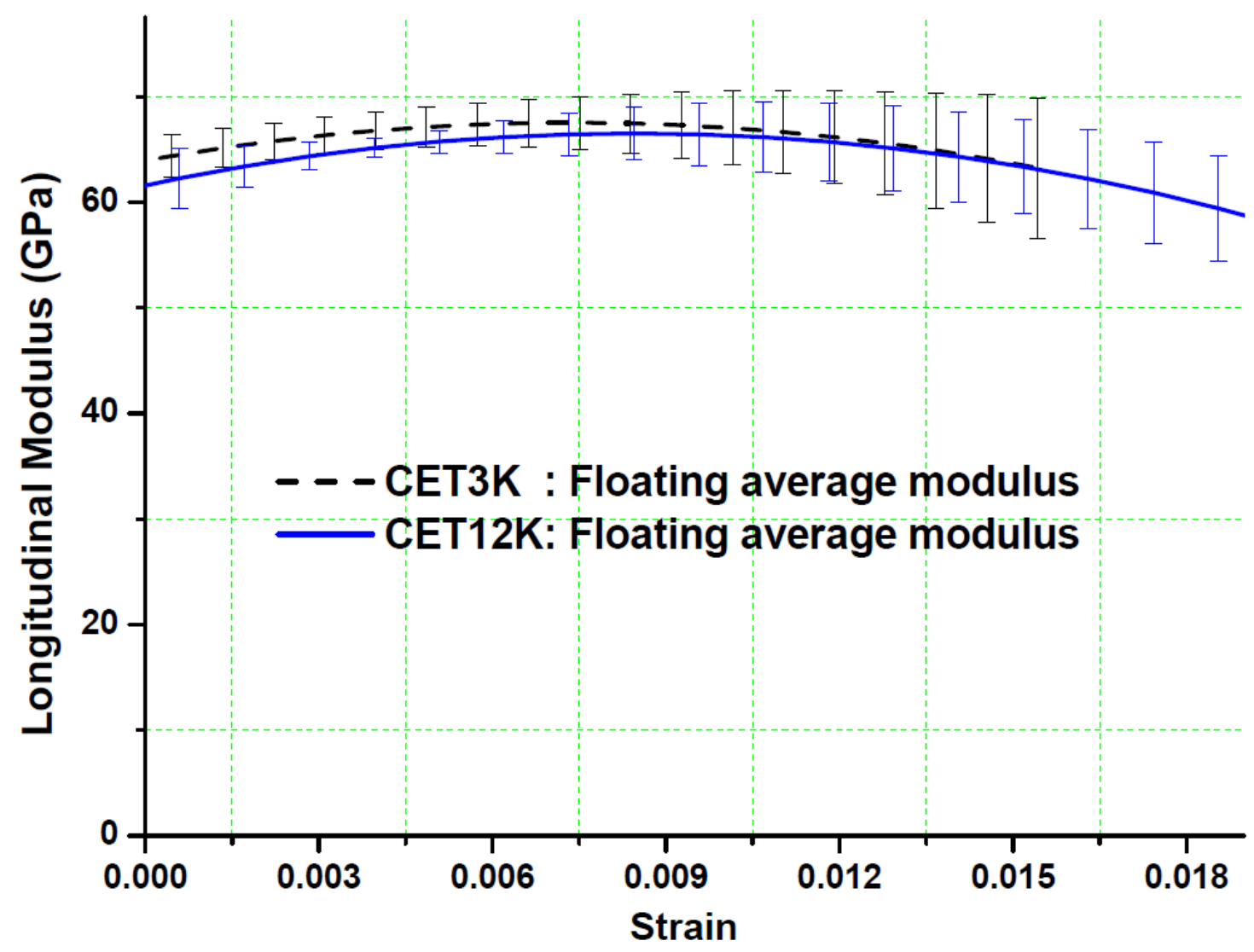

Figure 11: Non-linear strain-modulus diagrams of the CET3K and CET12K in the tensile test.

In Table 9, the Young's moduli of the two composites in the strain interval of $0.1 \%-0.3 \%$, in which no crucial damage occurs and the moduli are considered to be elastic, are compared to the homogenized longitudinal moduli calculated by FE-model and Mori-Tanaka method ${ }^{46}$, respectively. Apparently, the FE calculation provides a better prediction.

Table 9: Validation of the Young's modulus.

\begin{tabular}{lcccc}
\hline \hline & & $\operatorname{Exp}(0.1 \%-0.3 \%)$ & Mori-Tanaka & FEM \\
\hline $\operatorname{CET3K}\left(V_{f}=55.2 \%\right)$ & $(\mathrm{GPa})$ & $67.9 \pm 2.5$ & 69.2 & 67.2 \\
$\operatorname{CET12K}\left(V_{f}=53.6 \%\right)$ & & $65.3 \pm 2.6$ & 68.4 & 66.6 \\
\hline
\end{tabular}

\subsubsection{Damage in the weft yarn}


In the tensile tests, when the applied strain increases over $0.35 \%$, high energy release (from $10^{5}$ to $10^{6}$ - Figure 12 ) with very high density of acoustic events is recorded for CET3K samples. These high energy releases suggest a coalescence of cracks. The strain value, $0.35 \%$, is designated as a specific strain, $\varepsilon_{3 k}^{c r i t}$, for CET3K. For CET12K, the specific strain $\varepsilon_{12 k}^{c r i t}$ is delayed to $0.48 \%$. Before $\varepsilon_{3 k}^{\text {crit }}$, low energy acoustic events (lower than $2 \cdot 10^{3}$ ) are registered, which may correlate to the fibre-matrix micro-debonding.

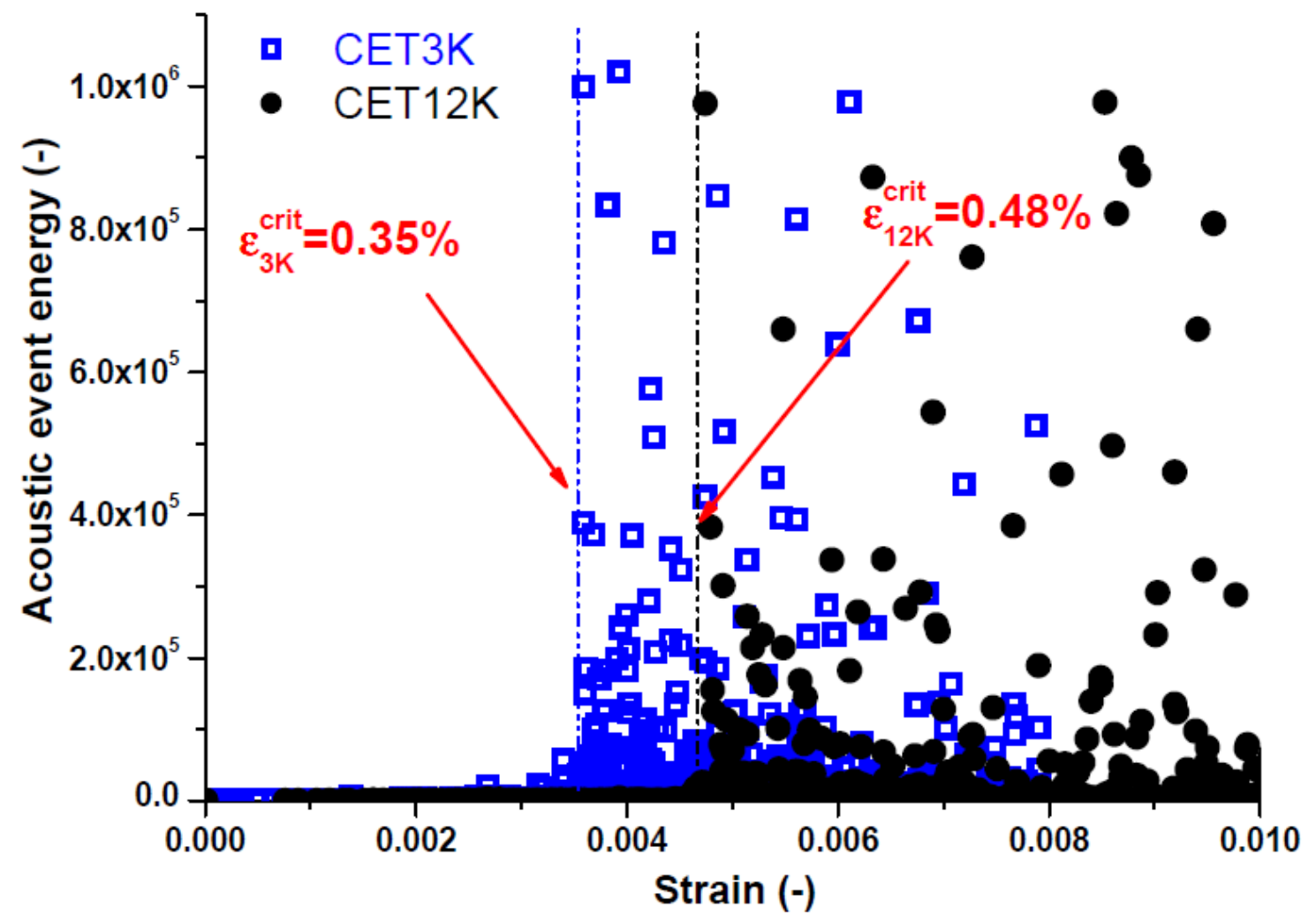

Figure 12: Acoustic events energy vs strain for CET3K and CET12K. The occurrence of higher energy events (from $10^{5}$ to $10^{6}$ ) with high density is used to determine the specific strain $\varepsilon^{\text {crit }}$.

Predicted by FE-model of twill weave composite ( Figure 13 ), the inter-fibre matrix cracks in the weft yarns of CET3K and CET12K occur when the external strain is $0.38 \%$ (the corresponding stress is 268MPa.) and $0.49 \%$ (334MPa), respectively. Figure 14 (a) shows the 
damage locations in the weft yarns (the brighter grey elements). Three elements [Figure 14 (b)] are further investigated to evaluate which stress component(s) contribute to the damage.

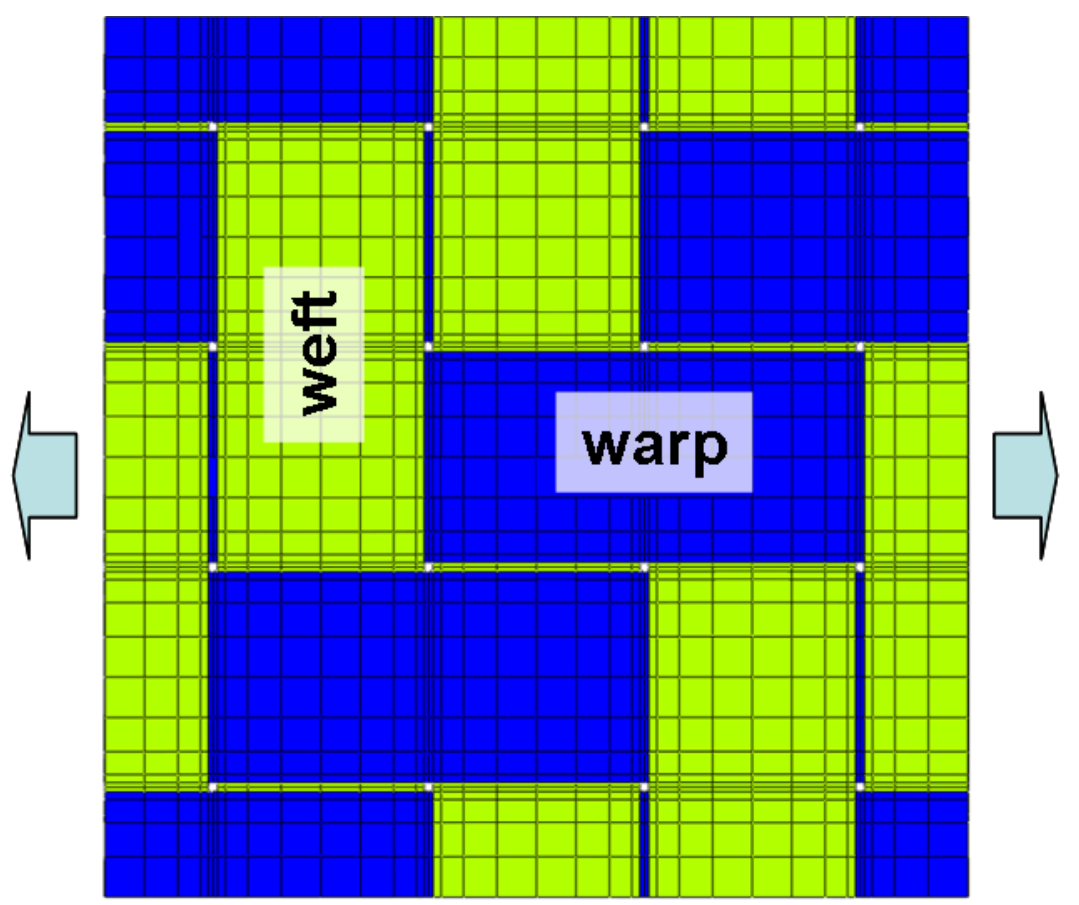

Figure 13: A unit cell of a twill weave composite with 19229 nodes and 16640 elements (the matrix elements are set invisible).

Table 10: Stress-to-strength ratios for three elements for CET3K just before damage (external strain $\varepsilon_{x x}=\mathbf{0 . 3 8 \%}$ ): out of damage zone (\#4187), and in the damage zone (\#4189 and \#4190)

\begin{tabular}{lcccccc}
\hline \hline No. & $\sigma_{11}^{2} / S_{1}^{c} S_{1}^{t}$ & $\sigma_{22}^{2} / S_{2}^{c} S_{2}^{t}$ & $\tau_{12}^{2} / S_{12}^{2}$ & $\sigma_{33}^{2} / S_{3}^{c} S_{3}^{t}$ & $\tau_{13}^{2} / S_{13}^{2}$ & $\tau_{23}^{2} / S_{23}^{2}$ \\
\hline$\# 4187$ & $1.2 \mathrm{E}-04$ & $4.9 \mathrm{E}-01$ & $1.4 \mathrm{E}-04$ & $1.2 \mathrm{E}-04$ & $1.2 \mathrm{E}-02$ & $1.2 \mathrm{E}-04$ \\
\hline$\# 4189$ & $6.1 \mathrm{E}-04$ & $7.8 \mathrm{E}-01$ & $2.2 \mathrm{E}-03$ & $2.5 \mathrm{E}-04$ & $4.0 \mathrm{E}-03$ & $1.2 \mathrm{E}-01$ \\
\hline$\# 4190$ & $2.0 \mathrm{E}-04$ & $7.4 \mathrm{E}-01$ & $9.3 \mathrm{E}-03$ & $2.5 \mathrm{E}-04$ & $3.1 \mathrm{E}-03$ & $9.0 \mathrm{E}-02$ \\
\hline
\end{tabular}




\section{external strain: $0.38 \%$ external stress: $268 \mathrm{MPa}$}

\section{center line}

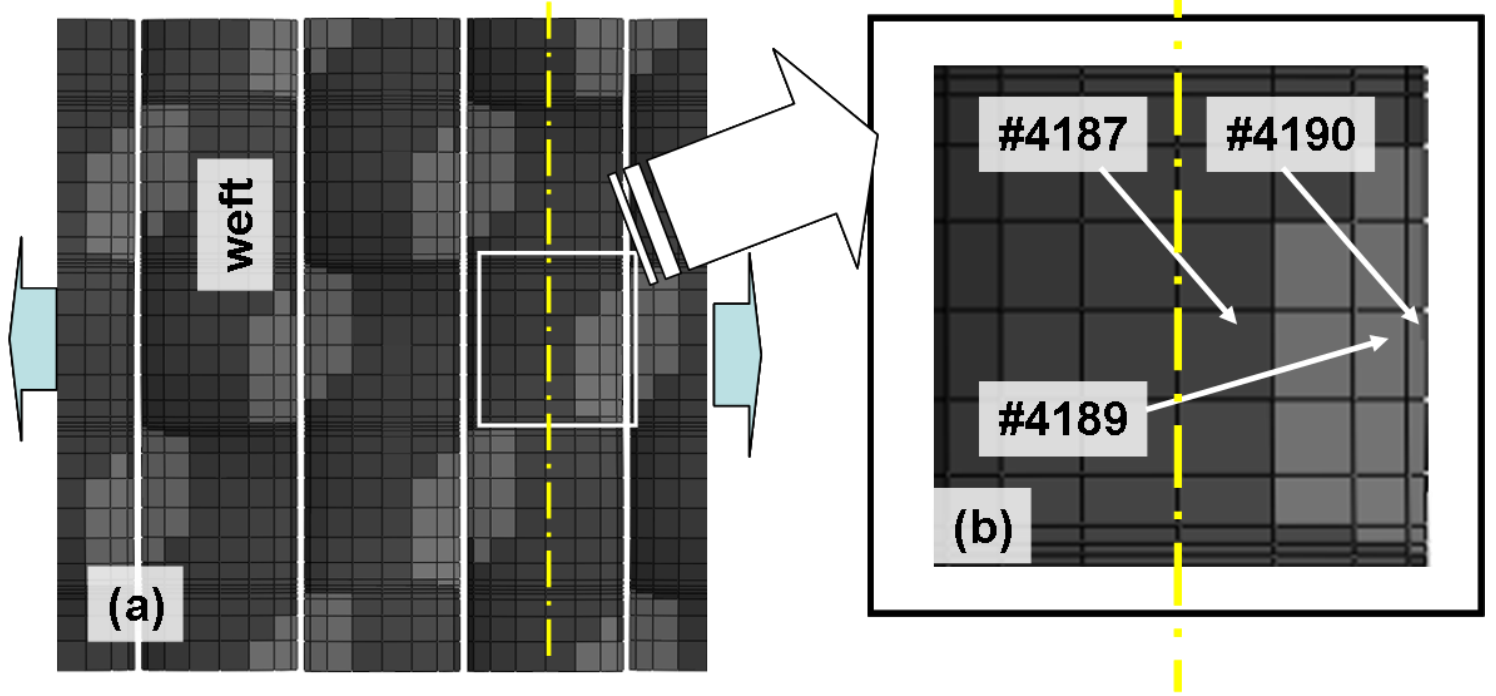

Figure 14: Damage initiation for CET3K under external strain $\varepsilon_{x x}=\mathbf{0 . 3 8 \%}\left(\sigma_{x x}=268 M P a\right)$,

the light grey elements represent damage zones: (a) Damage onset locations in weft yarns and (b) an amplified weft yarn, where the three elements are studied to investigate which stress component(s) contribute to the damage.

In Table 10, the stress-to-strength ratios are compared. As show in Figure 14 (b), element \#4187 is in between the center line of the weft yarn and the damage zone. Element \#4189 and \#4190 are in the damage zone, on the edge of the yarn. For these three elements, the largest stress-to-strength ratio is given by $\sigma_{22}$. Meantime, the out-of-plane shear stress $\tau_{23}$ for element \#4189 and \#4190 is 1000 times larger than that of element \#4187. Since the shear stress gradient is very steep, it is critical to qualitatively/precisely determine the shear stress value using linear hexahedral elements. Qualitatively, however, it indicates a drastic increase of out-of- plane shear effect in the damage area. A locally finer mesh or higher order elements can be used to deal with this problem, which requires a further development of the mesh generator. 
Figure 15 exhibits the stress contour for transverse fibre tensile stress $\sigma_{22}$ and out-of-plane shear stress $\tau_{23}$ just before the damage onset, in the weft yarns of CET3K. The locations of the maximum values of $\sigma_{22}$ and $\tau_{23}$ match very well to the locations of damage onset - Figure 14 (a). The out-of-plane shear stress drastically reaches to the maximum on the edge of the weft yarns, confirming the conclusions out of Table 10. When drawing a horizontal line crossing over the middle of the weft yarns - Figure 15 , the stress values $\left(\sigma_{22}\right.$ and $\left.\tau_{23}\right)$ vs normalized unit cell length can be plotted in Figure 16 .

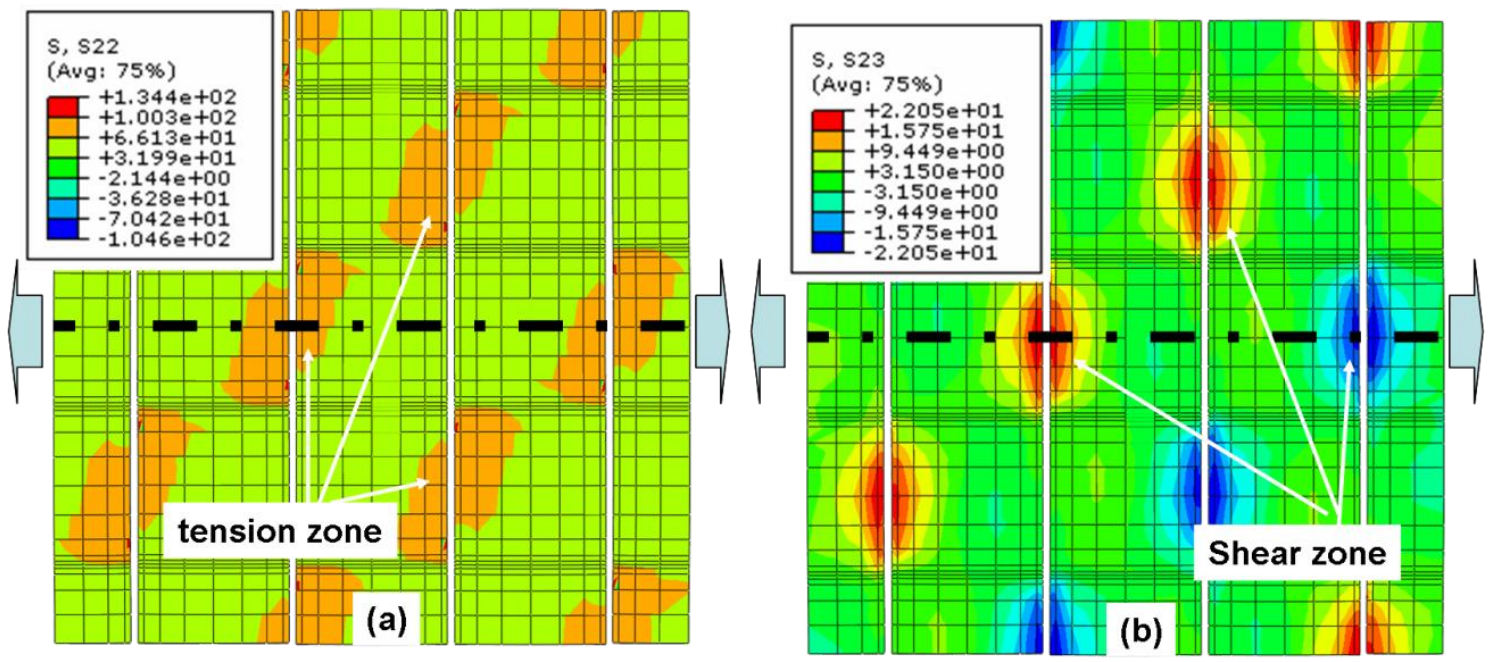

Figure 15: The stress contour in weft yarns for CET3K just before damage onset. The external strain is $\varepsilon_{x x}=0.38 \%\left(\sigma_{x x}=268 M P a\right)$. (a) $\sigma_{22}$ contour and (b) $\tau_{23}$ contour. 


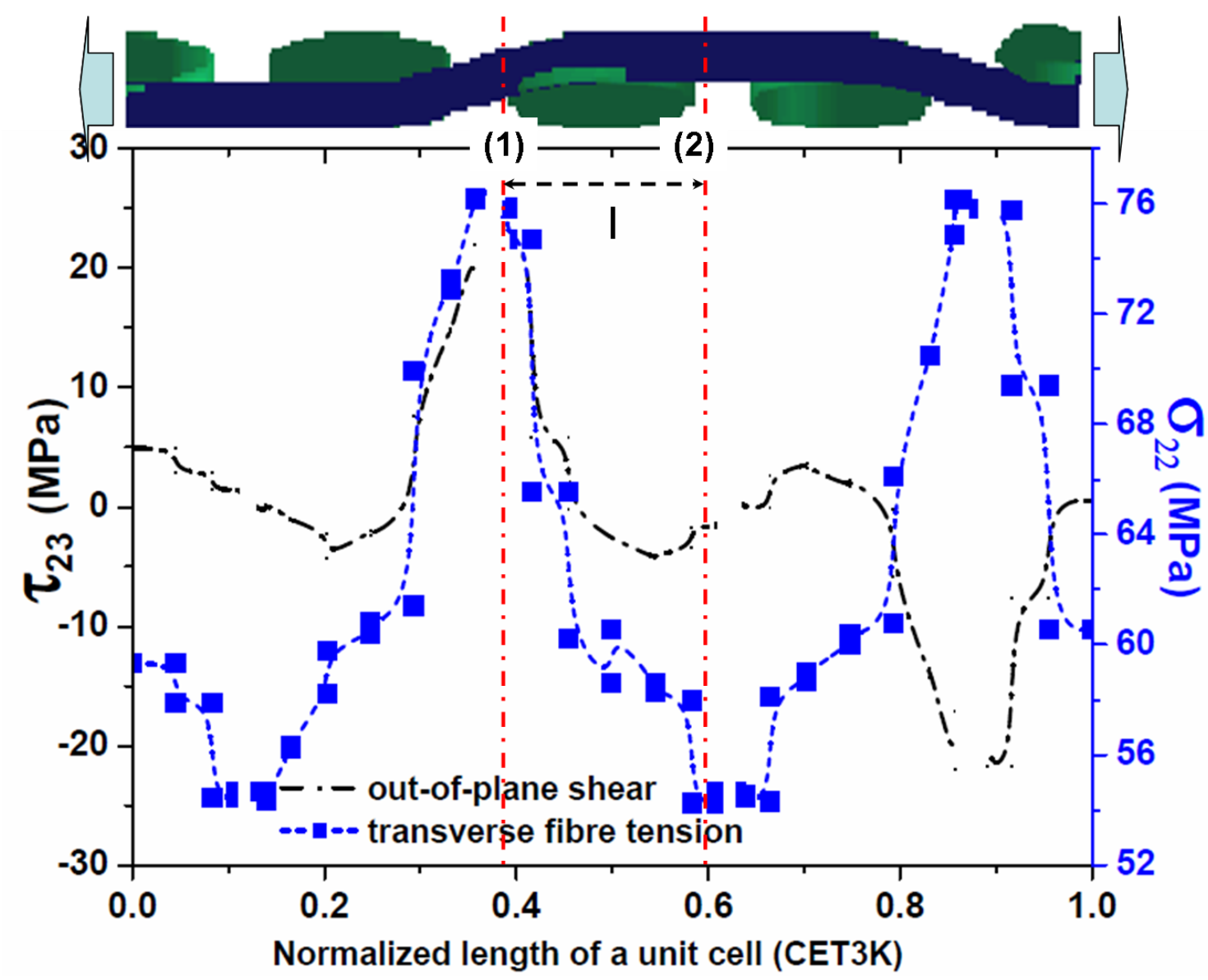

Figure 16: The transverse fibre tensile stress $\sigma_{22}$ and out-of-plane shear stress $\tau_{23}$ vs normalized length in the weft yarns for CET3K. The external strain is $\varepsilon_{x x}=\mathbf{0 . 3 8 \%}$ $\left(\sigma_{x x}=268 M P a\right)$.

The stress plot in Figure 16 shows good periodicity corresponding to that of the unit cell. The maximum values of $\sigma_{22}$ and $\tau_{23}$ occur on the edges of a weft yarn, where the warp yarn goes up from bottom of this weft yarn to the top of the adjacent weft yarn or vice versa. In zone I, $\sigma_{22}$ reduces from $76 \mathrm{MPa}$ to $54 \mathrm{MPa}$ when the measure point moving from place (1) where warp yarn has maximum crimp angle, to place (2) where the warp yarn is well aligned in the loading direction. At place (1), relatively higher portion of tension loading is taken by the weft yarns due to the high misalignment of the warp yarn. When the warp yarn gets gradually better alignment in the loading direction, the portion of load bore by weft yarn is reduced. The 
out-of-plane shear stress in the weft yarn reduces from the maximum, $25 \mathrm{MPa}$, at place (1) to zero at place (2). The shear effect is introduced by the warp yarn: higher crimp angle of warp yarn at place (1) induces higher out-of-plane shear effect to the weft yarn.

The stress distribution of CET $12 \mathrm{~K}$ are extracted at the external strain $\varepsilon=0.38 \%$, where no damage is predicted (CET3K is just before damage onset). These curves are compared with those of CET3K in Figure 17 and Figure 18 . In each figure, the shapes of the curves are basically similar. However, the curves of CET3K indicate much higher stress concentrations, on the edges of the weft yarns. In Figure 17 , the maximum $\sigma_{22}$ of CET3K is $77 \mathrm{MPa}, 10 \mathrm{MPa}(15 \%)$ large than that of CET12K. In Figure 18 , the maximum $\tau_{23}$ of CET3K is $25 \mathrm{MPa}$, twice of CET12K. Moreover, in zone I, the shear stress changes its sign from positive to negative, which indicates a bending effect imposed by warp to weft yarns.

As a summary, the higher crimp (CET3K) indeed introduces remarkable stress concentration (out-of-plane shear and transverse fibre tension) on the edges of the weft yarn, and the stress concentration leads to an earlier inter-fibre cracking. 


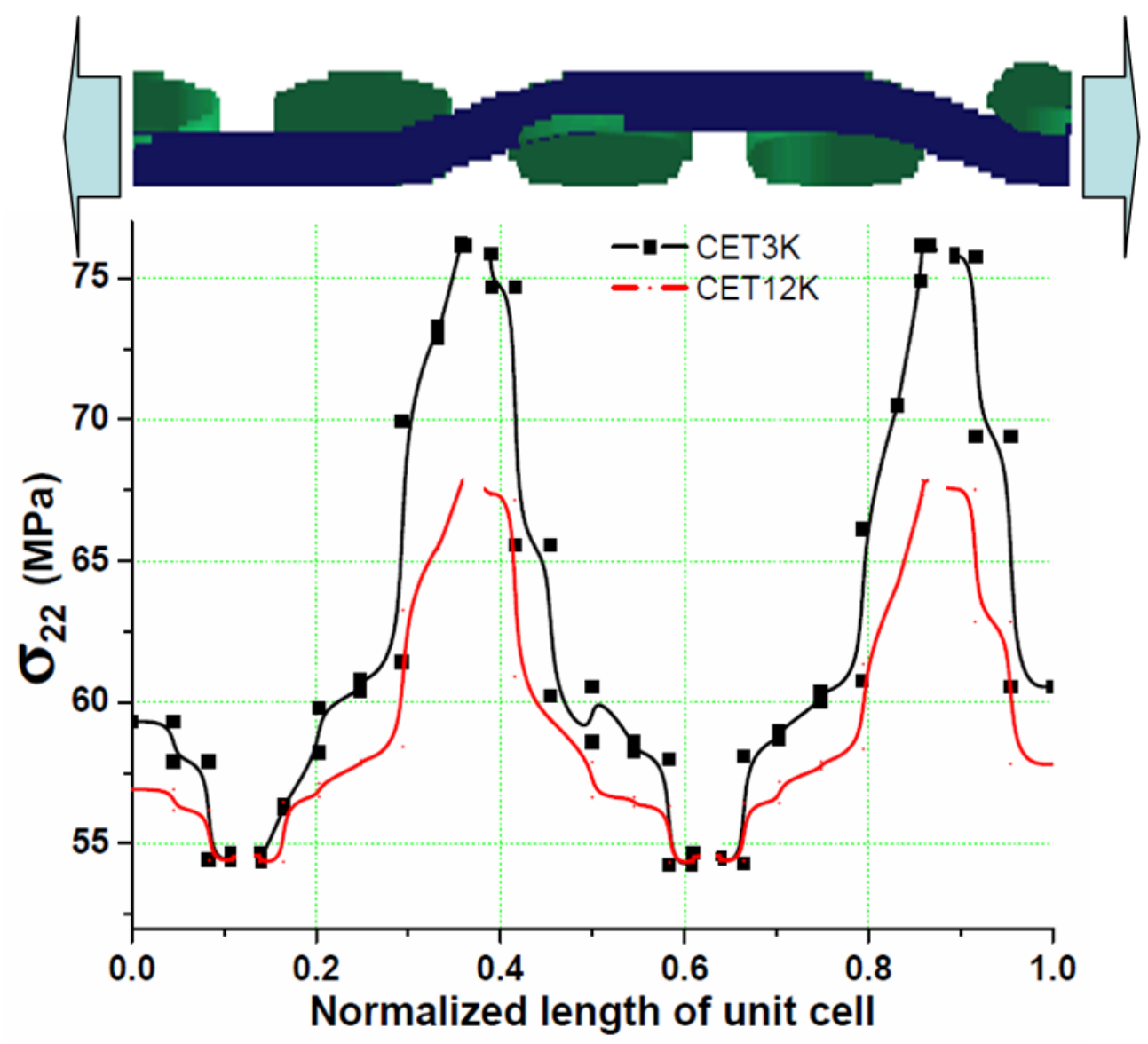

Figure 17: The transverse fibre tensile stress $\sigma_{22}$ vs normalized length of unit cell in the weft yarns of CET3K and CET12K. The external strain is $\varepsilon_{x x}=0.38 \%\left(\sigma_{x x}=268 M P a\right)$. 


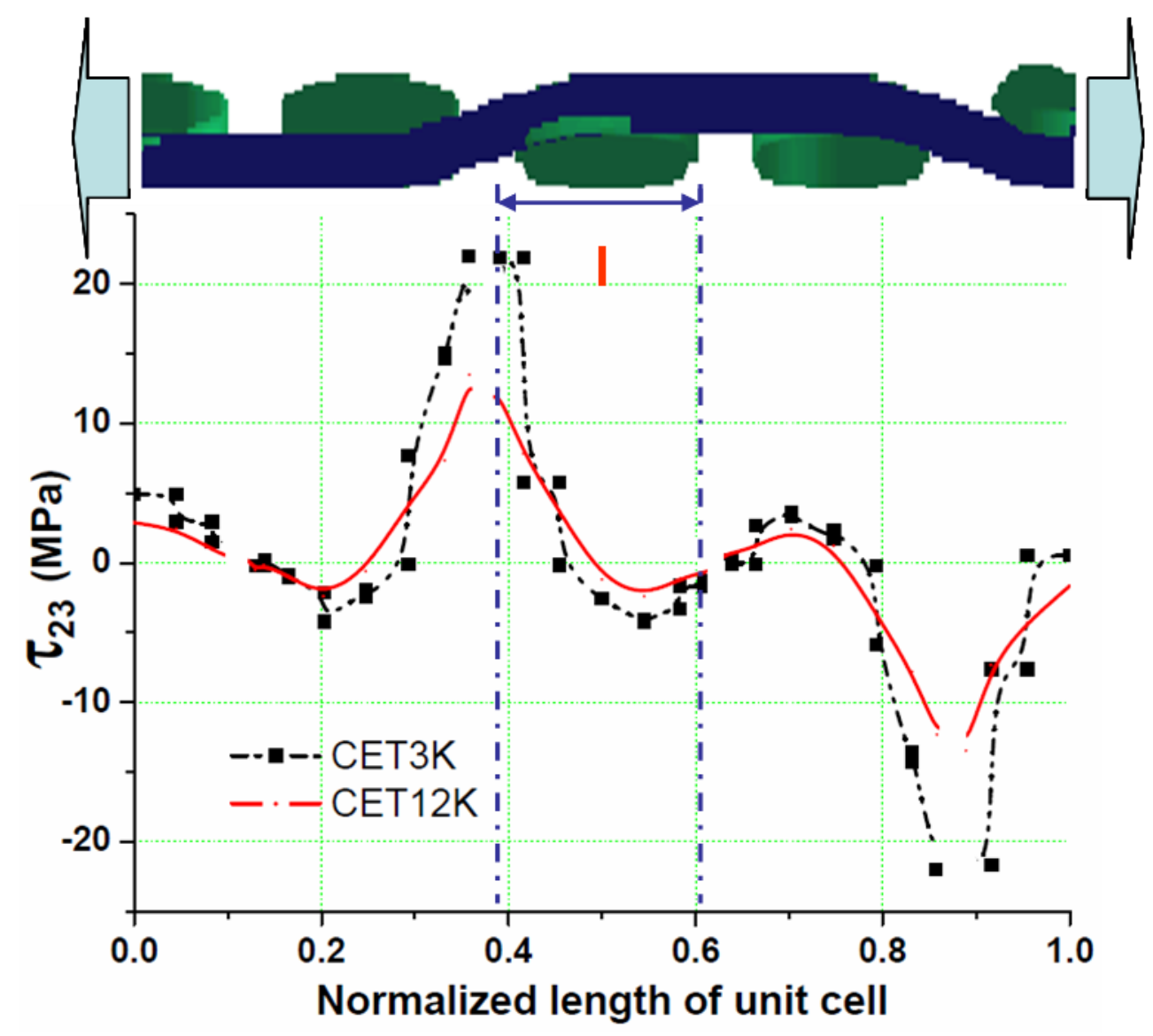

Figure 18: The out-of-plane shear stress $\tau_{23}$ vs normalized length of unit cell in the weft yarns of CET3K and CET12K. The external strain is $\varepsilon_{x x}=0.38 \%\left(\sigma_{x x}=268 M P a\right)$.

\subsubsection{Strength and ultimate strain}

The crimp is a typical structural feature of a woven laminate, which significantly reduces the strength and introduces a high nonlinear response due to the early damage initiation by high bending-torsion loading of the yarns ${ }^{10}$. Cross points of warp and weft yarns with high crimp are understood to be the place of weakness in the composites. Fibres under or over crossover points are under more tension and are more vulnerable to breakage ${ }^{47}$.

As listed in Table 11Table 6, the CET3K composite with smaller yarn size gives a higher crimp and, therefore, a lower static strength and lower ultimate strain compared to the CET12K composite. Having about the same fibre volume fraction, 54\%-55\%, CET3K has a strength of 
$960 \mathrm{MPa}$ lower than $1132 \mathrm{MPa}$ of CET12K; the ultimate strain is $1.45 \%, 0.35 \%$ lower than that of CET12K.

Table 11: Comparison of the strength and ultimate strain for CET3K and CET12K

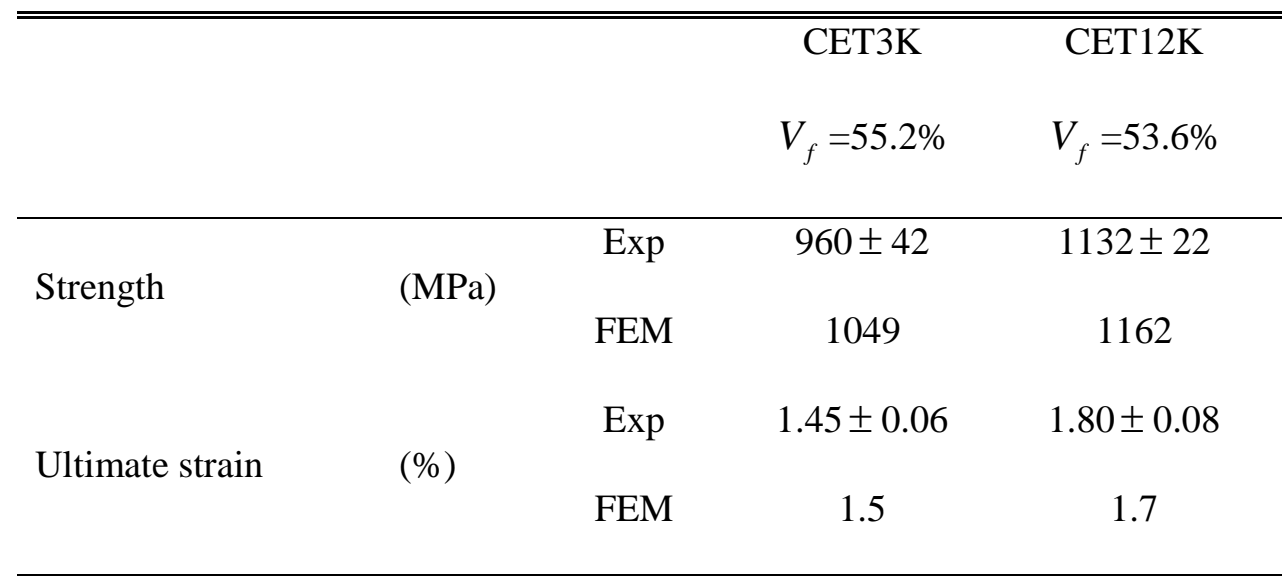

In Figure 19 and Figure 20 , the calculated strain-stress curves of CET3K and CET12K are plotted together with the experimental curves. Fairly good agreements are obtained.

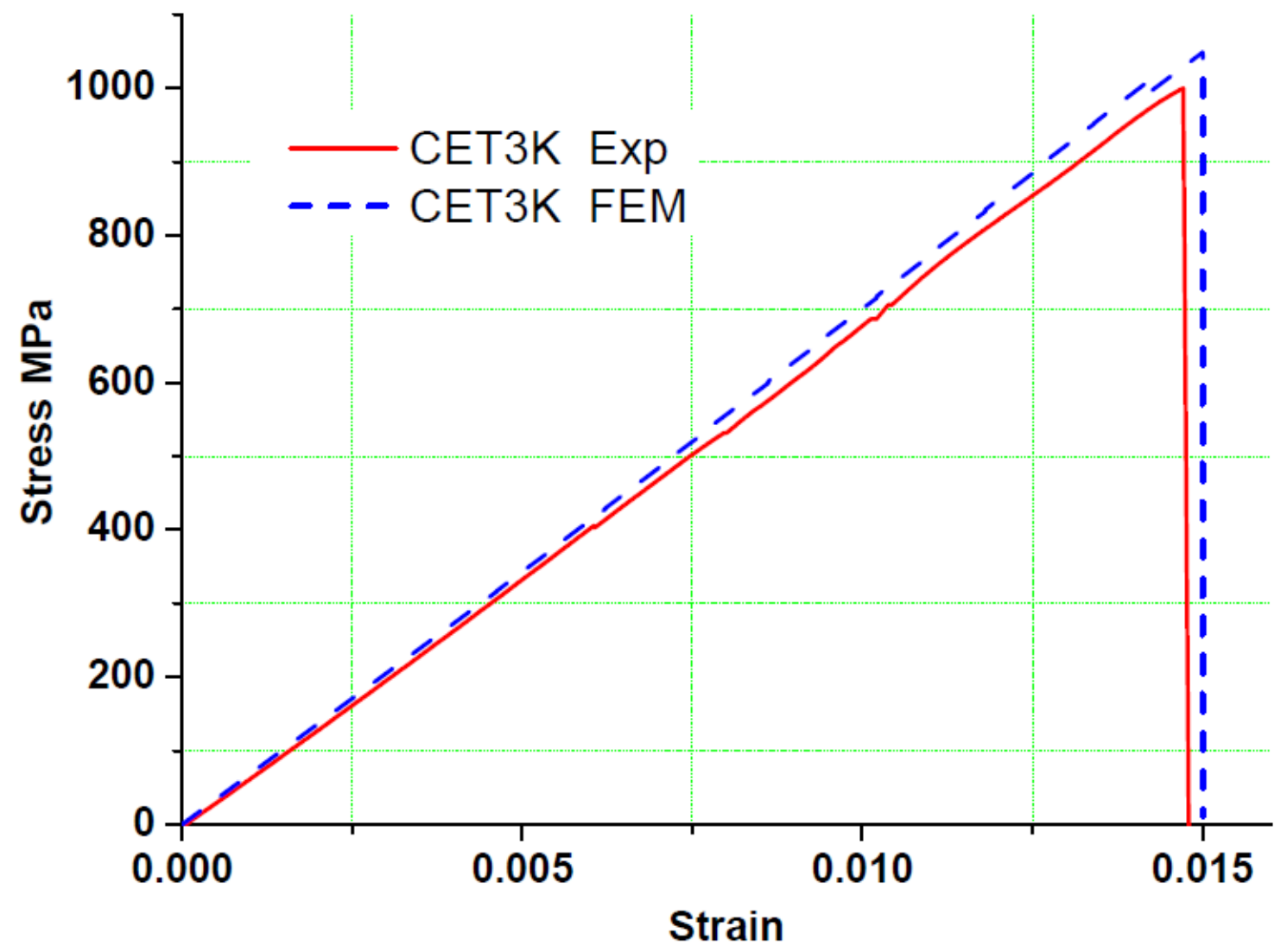

Figure 19: Validation of the strain-stress curves: CET3K 


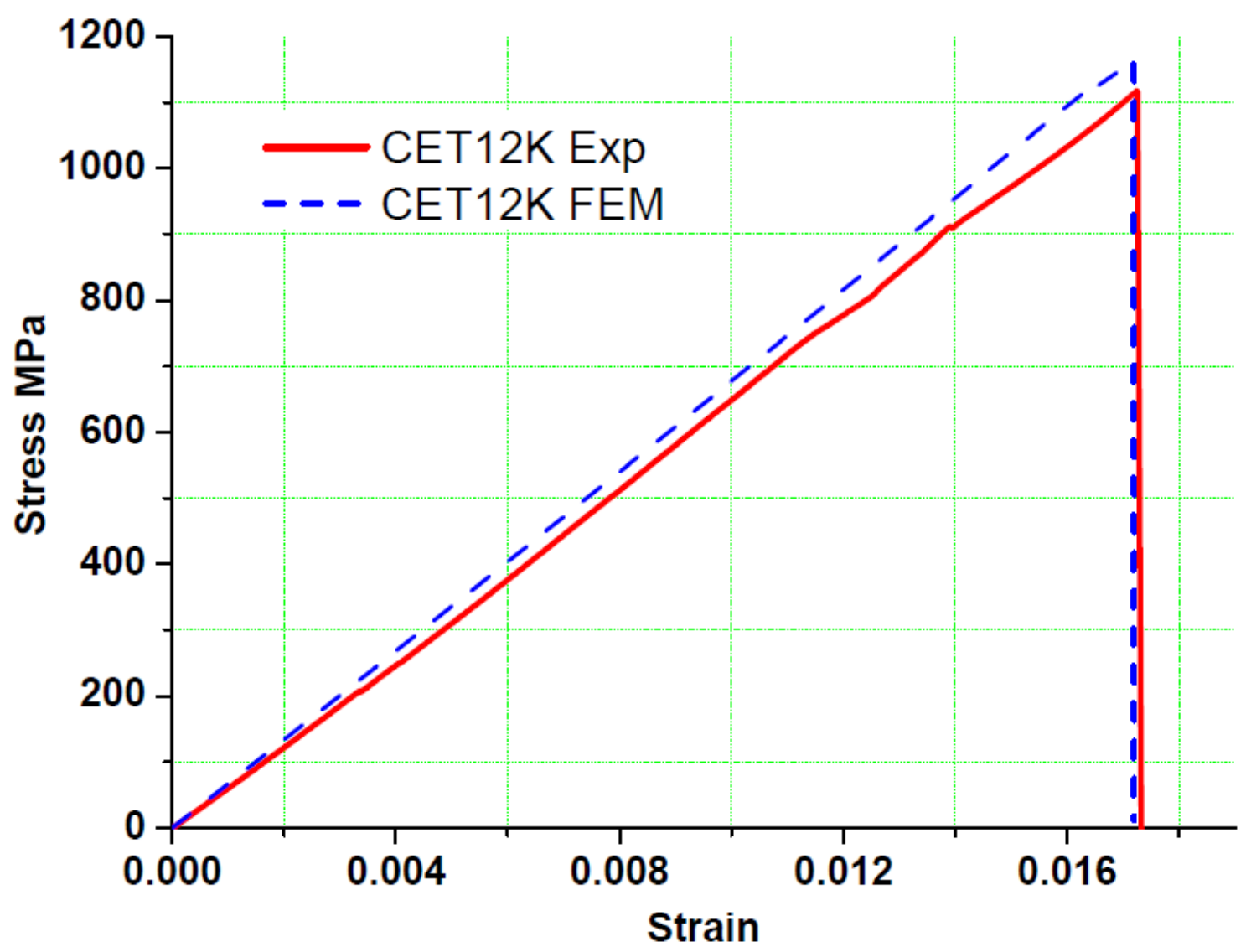

Figure 20: Validation of the strain-stress curves: CET12K

Under on-axis tensile loading, the sub-crucial damage accumulation has unremarkable effects to the packing geometry of the woven material. Hence the predicted ultimate loads are comparable, $6 \%$ different for CET3K for instance, to the predictions of full elastic model. In a like manner, the local load contours of an elastic model are very slightly different to those with material degradation (Figure 22, Figure 24 and Figure 24). However, the material degradation must be considered once off-axis external loadings have taken place.

\subsubsection{Fibre rupture}

\section{Fibre rupture locations}


Since the crimp introduces stress concentration to yarns, locally some locations undergo remarkably higher loads than the external loads. Figure 21 explains how the stress concentration is introduced to the warp yarns due to crimp.

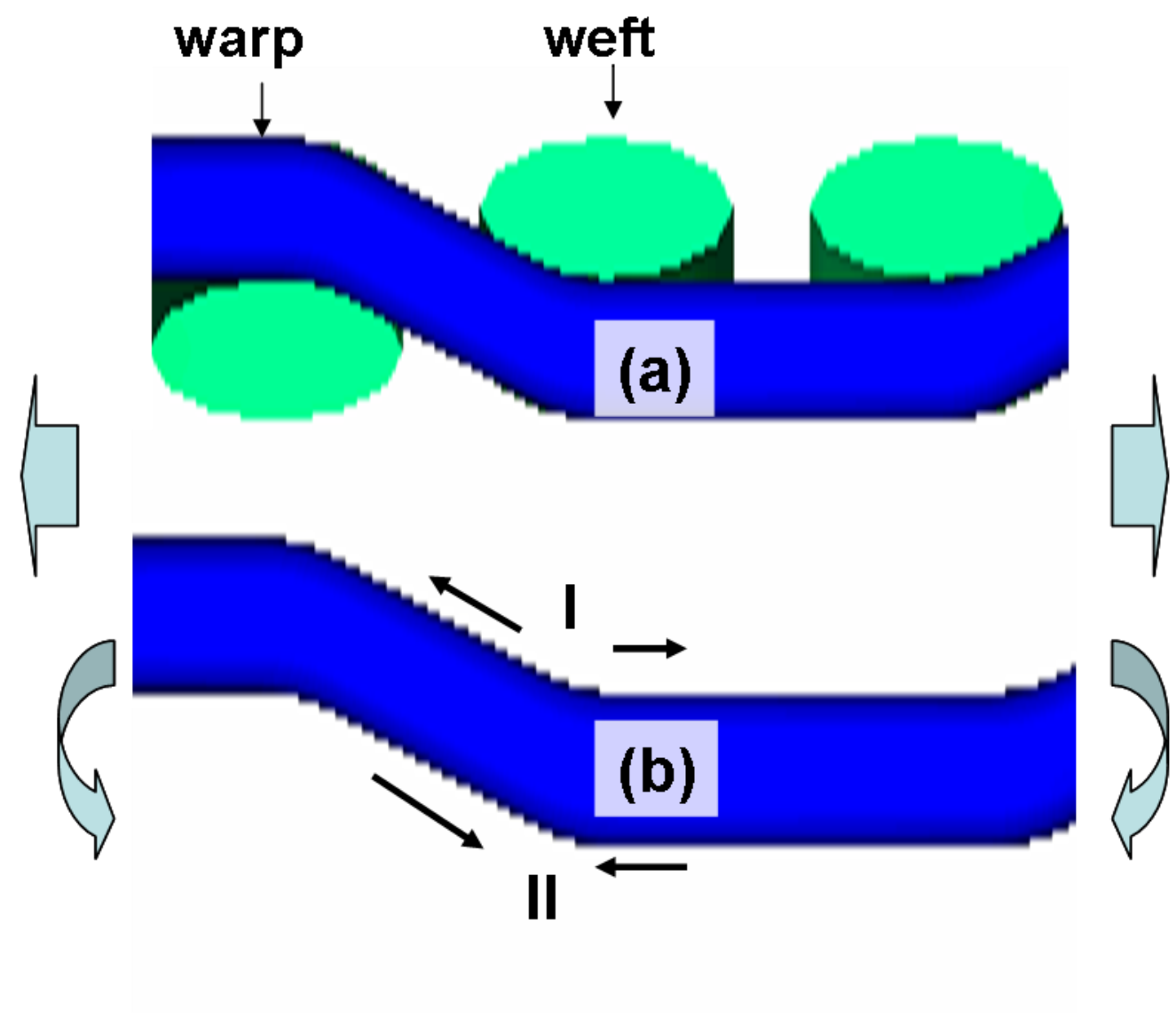

Figure 21: Stress concentration introduced by crimp in warp yarns: (a) a profile of impregnated twill weave preform in the composite; (b) bending effect and stress concentration at location I.

Figure 21 (a) shows a profile of the impregnated warp and weft yarns. The crimp is introduced due to the yarns' interlock. Under external tensile loading, the impregnated warp yarn experiences, however, a bending effect - Figure 21 (b). Location I experiences more tension than the external loading (stress concentration), while location II experiences less. Moreover, it hints that ideally the fibre rupture will initiate at the location where (1) warp yarn and weft yarn have a contact surface, and (2) the warp yarn has the largest curvature. 
Figure 22 (a) exhibits a meso-FE model of CET12K without resin. The model clearly predicts the pattern of rupture locations in warp yarns - Figure 22 (c). Locations (1)-(4) in Figure 22 (a) represent four locations where the ruptures possibly occur according to the description in Figure 21. However, ruptures start at locations (1) and (3) [Figure 22 (c)] instead of (2) and (4). The strain profile [Figure 22 (b)] also confirms that the maximum local strains occur at locations (1) and (3). 


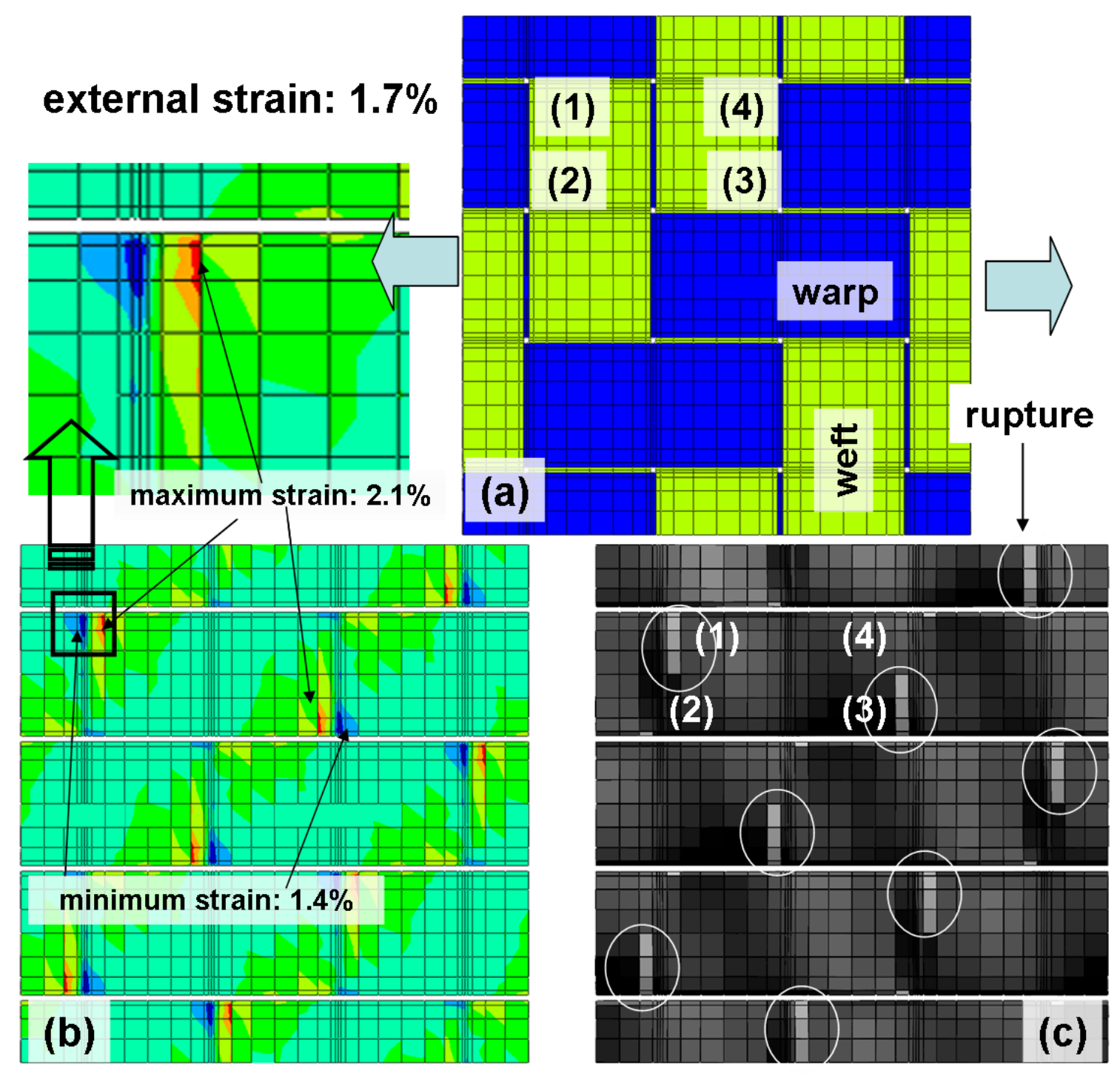

Figure 22: Fibre rupture and final failure under external strain $\varepsilon_{x x}=1.7 \%$ : (a) meso-FE mode of CET12K; (b) profile of strain $\varepsilon_{11}$ shows the locations of the maximum strains and minimum strains, which are less than the external strain; (c) locations of fibre rupture.

Under external tensile loading, the warp yarn A [Figure 23 (a)] presses the weft yarn B inward paper direction. This compression effect is then passed to the neighboring warp yarn C. On the warp yarn C [Figure 23 (b)], location (3) experiences slightly more compression than location (4). Therefore, location (3) has a higher curvature than location (4). As a result of this higher curvature, the fibre rupture initiates at location (1) and location (3). In contrast, for plain weave 
composites, the rupture onset locations are symmetrically distributed on the warp yarns due to the even curvatures in the symmetric positions - Figure 24 .

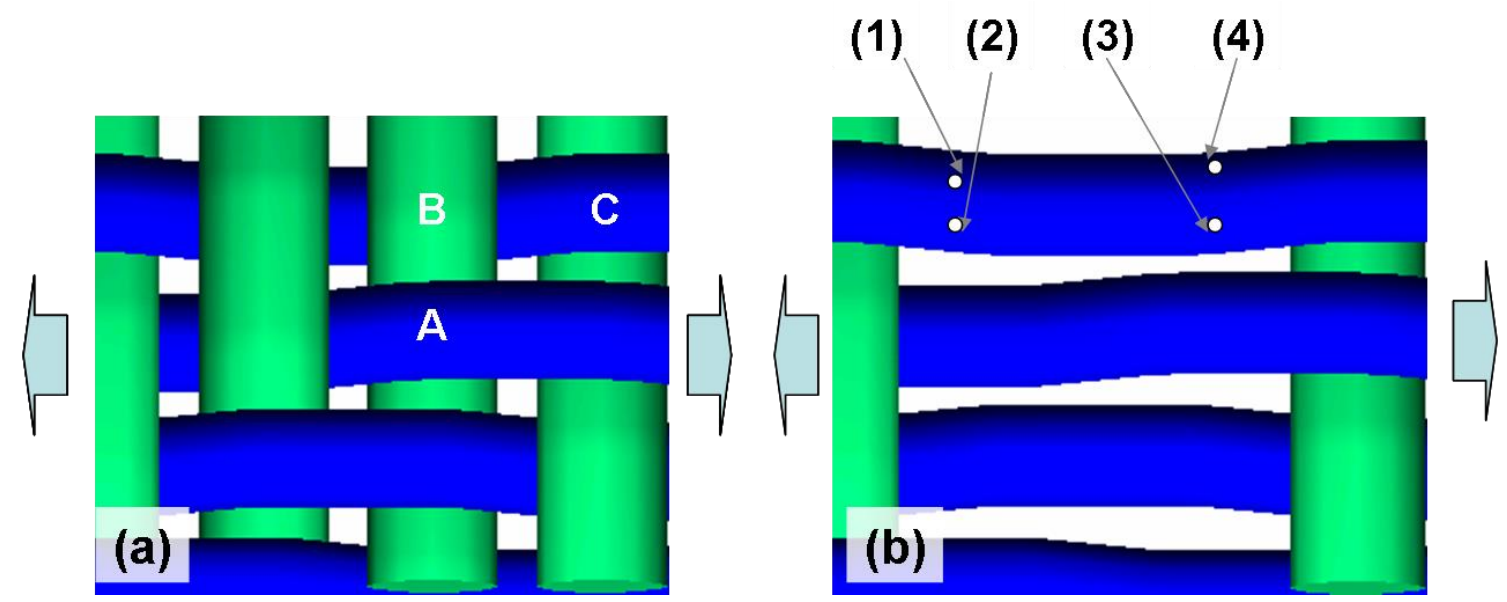

Figure 23: Locations of the fibre rupture: (a) unit cell of CET12K, (b) the possible fibre rupture locations on warp yarns.

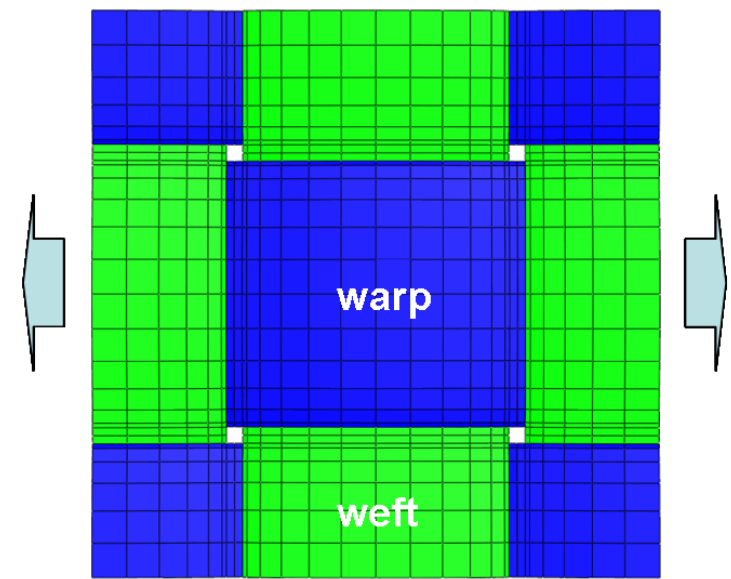

(a)
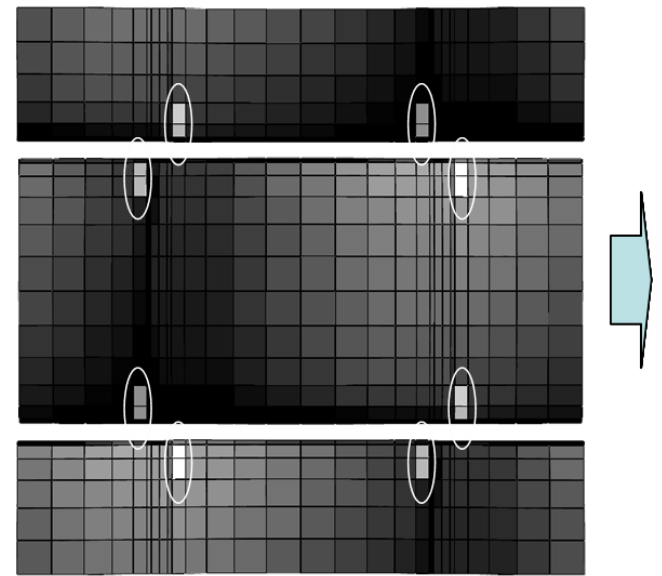

(b)

Figure 24: Locations of the fibre rupture for PW12K: (a) unit cell of PW12K, (b) the symmetric locations on warp yarns. 
The fibre rupture pattern for CET3K is shown in Figure 25 (a). In Figure 25 (b) and Figure 25 (c), the strain contours (local strain, $\varepsilon_{11}$ ) in the warp yarns of CET3K and CET12K are also provided. The applied external strain is $1.5 \%$ just before the final failure of CET3K.
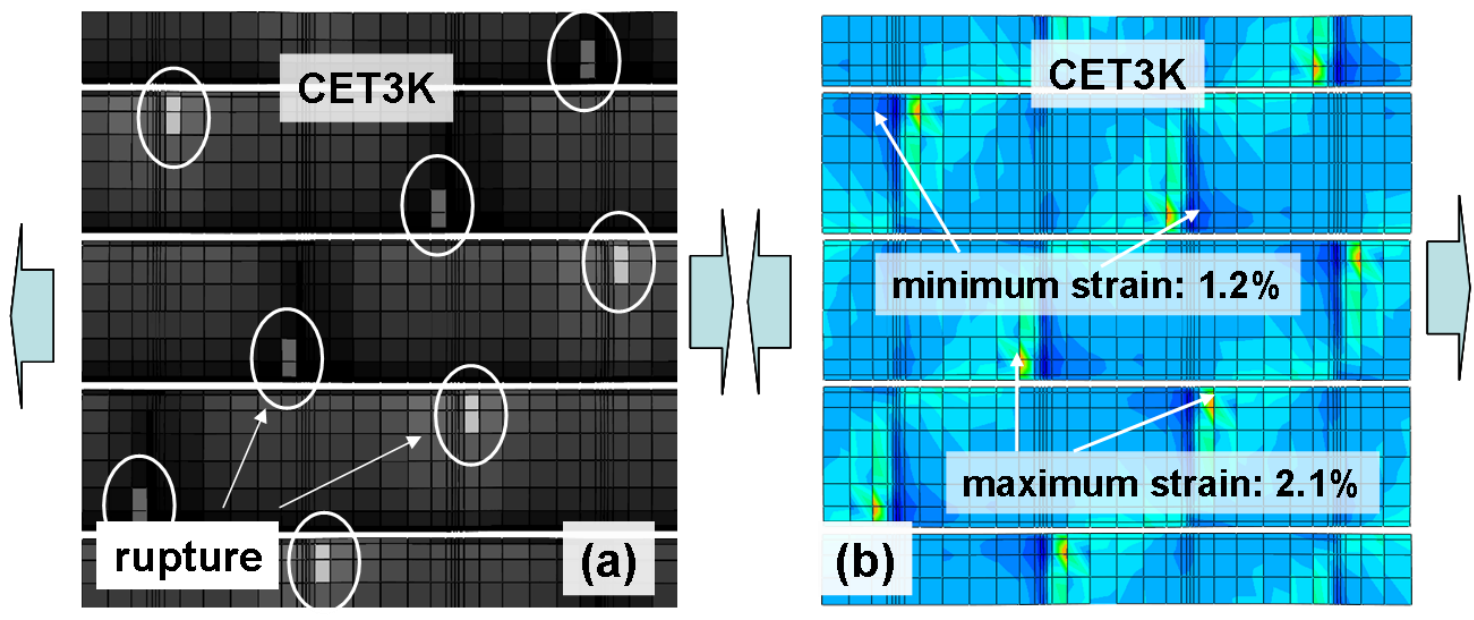

\section{external strain: $1.5 \%$}
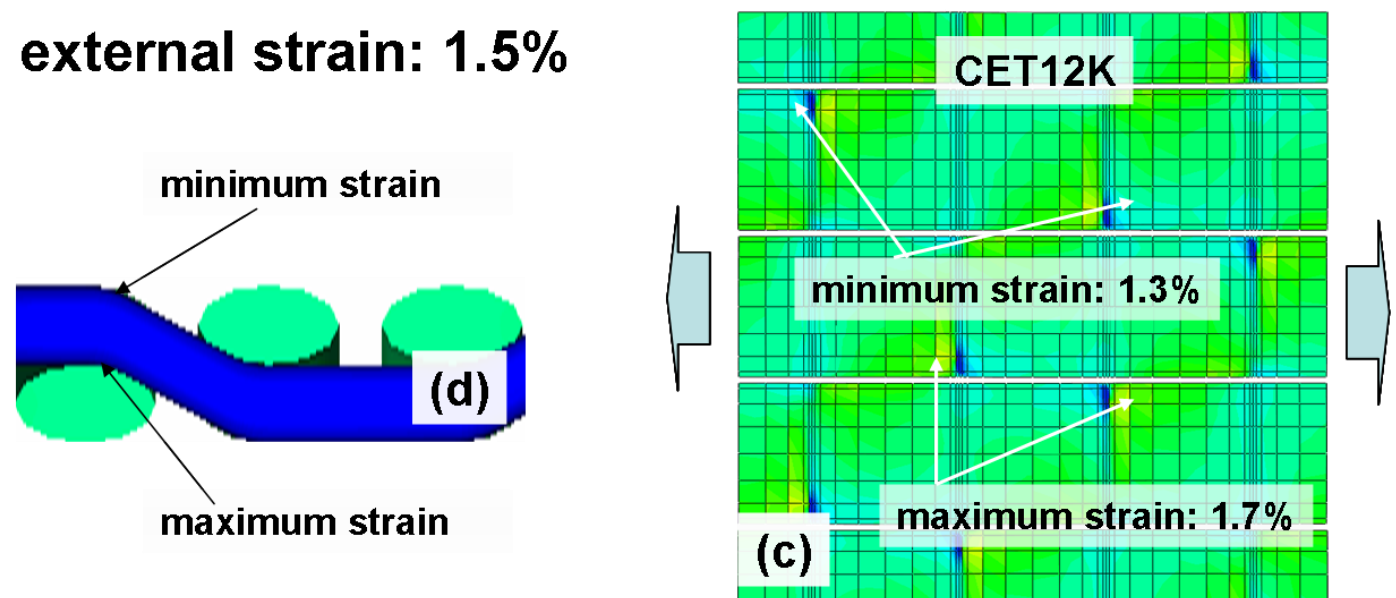

Figure 25: Comparison of the local strain $\varepsilon_{11}$ profiles in the warp yarns of CET3K and CET12K at external strain $\varepsilon_{x x}=\mathbf{1 . 5 \%}$ (just before the final failure of CET3K): (a) fibre rupture locations for CET3K, (b) local strain $\varepsilon_{11}$ profile for CET3K as well as maximum (2.1\%) and minimum (1.2\%) strain locations, (c) local strain $\varepsilon_{11}$ profile for CET12K with maximum (1.7\%) and minimum strain $(1.3 \%)$ locations (d) minimum and maximum strain locations on an impregnated warp yarn. 
The damage pattern of CET3K is the same as that of CET12K, shown in Figure 22 (c). However, it is revealed that the higher crimp for CET3K introduces a much higher maximum local strain $\left(\varepsilon_{11}=2.1 \%\right)$ than in CET12K $\left(\varepsilon_{11}=1.7 \%\right)$. This maximum local strain leads to an earlier fibre rupture in CET3K.

The minimum strain locations are next to the maximum strain, at the convex part of the curvature - Figure 25 (d), where a warp yarn just goes onto the top of a weft yarn. The higher the curvature is, the lower the corresponding minimum strain is. Hence CET3K has a smaller minimum strain value (1.2\%) than that of CET12K (1.3\%) - Figure 25 (b)(c).

\section{CONCLUSIONS}

In this paper, a meso-scale progressive static damage model for textile composite materials has been established. The following problems are solved:

1. The meso-FE geometrical models of textile composites are established.

2. The impregnated yarns are taken as a homogeneous and transverse isotropic material and its properties are calculated using Chamis' equations. The strain-stiffening effect of carbon fibre is considered.

3. There are four damage modes: one for fibre rupture and three for inter-fibre matrix cracking. Tsai-Wu criterion and additional criteria proposed by $\mathrm{Zako}^{11}$ are used to determine the damage modes.

4. The Murakami damage tensor ${ }^{19}$ is used to calculate the post-damage stiffness.

5. The modelling work is preliminarily validated by experimental data of plain weave carbon/epoxy composites from literature.

Two types of twill weave carbon/epoxy composite materials have been experimentally investigated via quasi-static tensile tests accompanied by strain mapping and acoustic emission. The apparent properties were compared with the numerical results, and good agreements are obtained. From the experiments, the following conclusions can be drawn: 
1. Strength is very sensitive to crimp: woven composite with higher crimp tends to have lower strength.

2. Stiffness has no clear dependence on the crimp.

3. The plot of cumulative acoustic energy and the density of the acoustic events indicate that CET3K has an earlier damage initiation than CET12K.

Furthermore, the FE-model is used to study the damage locations in the weft yarns (damage onset) and in the warp yarns (final failure). A comparative study for CET3K and CET12K on crimp-introduced stress concentration is carried out by using the FE model as well. With the help of the model, the study shows that:

1. The transverse fibre tensile stress and the out-of-plane shear stress play crucial roles in the formation of the inter-fibre matrix cracks in the weft yarns.

2. Under tensile loading, at the crimp spots, the impregnated warp yarns experience bending effects, which introduce the stress concentration and hence the fibre rupture.

3. A higher crimp promotes both the inter-fibre crack and fibre rupture.

The local load contours and the ultimate loads are insensitive to the damage accumulation introduced material degradation when the model is under an on-axis external load. However, the material degradation becomes crucial once complex load has to be taken into consideration. Damage in textile composite, most of the time, is due to stress concentration. In order to succeed a precise prediction, a further development of the preprocessor with local finer mesh and higher order elements are necessary.

\section{ACKNOWLEDGEMENTS}

This work is financed by F.W.O. G.0233.06N project under the cooperation between the 
Department of Metallurgy and Materials Engineering in KULeuven, and Department of Materials Science and Engineering in Ghent University. The support from collaborators of both departments and from Dr. Satoshi Hanaki, Professor Masaru Zako is highly noted.

\section{REFERENCES}

1. Chou T-W and Ko FK. Textile structural composites. Amsterdam ; Oxford: Elsevier, 1989, p.xii, 387 p.

2. Naik NK. Woven fabric composites. Lancaster, Pa.: Technomic Pub. Co., 1994, p.xi, $193 \mathrm{p}$.

3. Naik RA. Failure analysis of woven and braided fabric reinforced composites. Journal of Composite Materials. 1995; 29: 2334-63.

4. Bogdanovich AE. Multi-scale modeling, stress and failure analyses of 3-D woven composites. Journal of materials science. 2006; 41: 6547-90.

5. Fish J and Yu Q. Two-scale damage modeling of brittle composites. Composites Science and Technology. 2001; 61: 2215-22.

6. Karkkainen RL and Sankar BV. A direct micromechanics method for analysis of failure initiation of plain weave textile composites. Composites Science and Technology. 2006; 66: 137-50.

7. Tang X, Whitcomb JD, Kelkar AD and Tate J. Progressive failure analysis of $2 \times 2$ braided composites exhibiting multiscale heterogeneity. Composites Science and Technology. 2006; 66: 2580-90.

8. Greve L and Pickett AK. Modelling damage and failure in carbon/epoxy non-crimp fabric composites including effects of fabric pre-shear. Composites Part A: Applied Science and Manufacturing. 2006; 37: 1983-2001.

9. Lomov SV, Ivanov DS, Verpoest I, et al. Meso-FE modelling of textile composites: Road map, data flow and algorithms. Composites Science and Technology. 2007; 67: 1870-91.

10. Nicoletto $G$ and Riva E. Failure mechanisms in twill-weave laminates: FEM predictions vs. experiments. Composites Part A: Applied Science and Manufacturing. 2004; 35: 787-95.

11. Zako M, Uetsuji Y and Kurashiki T. Finite element analysis of damaged woven fabric composite materials. Composites Science and Technology. 2002; 63: 507-16.

12. Kollegal MG and Sridharan S. Compressive behavior of plain weave lamina. Journal of Composite Materials. 1998; 32: 1334-55.

13. Dasgupta A and Bhandarkar SM. EFFECTIVE THERMOMECHANICAL BEHAVIOR OF PLAIN-WEAVE FABRIC-REINFORCED COMPOSITES USING HOMOGENIZATION THEORY. Journal of Engineering Materials and Technology-Transactions of the Asme. 1994; 116: 99-105.

14. Hamelin P and Bigaud D. A numerical procedure for elasticity and failure behavior prediction of textile-reinforced composite materials. Journal of Thermoplastic Composite Materials. 1999; 12: 201-13. 
15. Kyeongsik W and Whitcomb JD. Three-dimensional failure analysis of plain weave textile composites using a global/local finite element method. Journal of Composite Materials|Journal of Composite Materials. 1996; 30: 984-1003.

16. Whitcomb J and Srirengan K. Effect of various approximations on predicted progressive failure in plain weave composites. Composite Structures. 1996; 34: 13-20.

17. Blackketter DM, Walrath DE and Hansen AC. MODELING DAMAGE IN A PLAIN WEAVE FABRIC-REINFORCED COMPOSITE-MATERIAL. Journal of Composites Technology \&amp; Research. 1993; 15: 136-42.

18. Carvelli V and Poggi C. A homogenization procedure for the numerical analysis of woven fabric composites. Composites Part A: Applied Science and Manufacturing. 2001; 32: 1425-32.

19. Murakami S. Mechanical Modeling of Material Damage. Journal of Applied Mechanics. 1988; 55: 280-6.

20. Hanaki S, Lomov SV, Verpoest I, Zako M and Uchida H. Estimation of fatigue life for textile composites based on fatigue test for unidirectional materials. Finite element modelling of textiles and textile composites.

21. Lomov SV, Gusakov AV, Huysmans G, Prodromou A and Verpoest I. Textile geometry preprocessor for meso-mechanical models of woven composites. Composites Science and Technology. 2000; 60: 2083-95.

22. Verpoest I and Lomov SV. Virtual textile composites software WiseTex: Integration with micro-mechanical, permeability and structural analysis. Composites Science and Technology. 2005; 65: 2563-74.

23. Kurashiki T, Nakai H, Hirosawa S, et al. Mechanical Behaviours for Textile Composites by FEM Based on Damage Mechanics. Key Engineering Materials. 2007; Volumes 334 - 335: 257-60.

24. Kurashiki T, Zako M, Nakai H, et al. A practical numerical simulation system of mechanical behaviour of composites. Proc ECCM-12, 12th European Conference on Composite Materials.

25. Lomov SV, Ding X, Hirosawa S, et al. FE simulations of textile composites on unit cell level: validation with full-field strain measurements. Proc SAMPE Europe International Conference 2005. p. 28-33.

26. Shioya M, Hayakawa E and Takaku A. Non-hookean stress-strain response and changes in crystallite orientation of carbon fibres. Journal of materials science. 1996; 31: 4521-32.

27. Toyama $\mathrm{N}$ and Takatsubo J. An investigation of non-linear elastic behavior of CFRP laminates and strain measurement using Lamb waves. Composites Science and Technology. 2004; 64: 2509-16.

28. Ivanov DS, Ivanov SG, Lomov SV and Verpoest I. Unit cell modelling of textile laminates with arbitrary inter-ply shifts. Composites Science and Technology. 2011; 72: 14-20.

29. Kurashiki T, Zako M, Hirosawa S, Lomov SV and Verpoest I. Estimation of a mechanical characterization for woven fabric composites by fem based on damage mechanics. ECCM-11, 11th European Conference on Composite Materials.

30. Pellegrino C, Galvanetto $U$ and Schrefler BA. Numerical homogenization of periodic composite materials with non-linear material components. International Journal for Numerical Methods in Engineering. 1999; 46: 1609-37. 
31. Wang XF, Wang XW, Zhou GM and Zhou CW. Multi-scale analyses of 3D woven composite based on periodicity boundary conditions. Journal of Composite Materials. 2007; 41: 1773-88.

32. Chamis CC. MECHANICS OF COMPOSITE-MATERIALS - PAST, PRESENT, AND FUTURE. Journal of Composites Technology \&amp; Research. 1989; 11: 3-14.

33. Rosen BW. Mechanics of composite strengthening. In: Fiber Composite Materials. Metals Park (OH): ACM. 1965.

34. Hirai $\mathrm{T}$ and Yoshida $\mathrm{H}$. The effect of moulding on the mechanical properties of FRP. Journal of the Society of Materials Science, Japan|Journal of the Society of Materials Science, Japan. 1974; 23: 954-9.

35. Tsai SW and Wu EM. A general theory of strength for anisotropic materials. Journal of Composite Materials. 1971; 5: 55-80.

36. Tsai SW. Theory of composites design. Think Composites, 1992.

37. Gorbatikh L, Ivanov D, Lomov S and Verpoest I. On modelling of damage evolution in textile composites on meso-level via property degradation approach. Composites Part A: Applied Science and Manufacturing. 2007; 38: 2433-42.

38. Nishikawa $Y$, Okubo K, Fujii $T$ and Kawabe K. Fatigue crack constraint in plain-woven CFRP using newly-developed spread tows. International Journal of Fatigue. 2006; 28: 1248-53.

39. Truong TC, Ivanov DS, Klimshin DV, Lomov SV and Verpoest I. Carbon composites based on multi-axial multi-ply stitched preforms. Part 7: Mechanical properties and damage observations in composites with sheared reinforcement. Composites Part A: Applied Science and Manufacturing. 2008; 39: 1380-93.

40. Kelly $\mathrm{A}$ and Zweben $\mathrm{CH}$. Comprehensive Composite Materials: Fiber reinforcements and general theory of composites. Elsevier, 2000.

41. Curtis GJ, Milne JM and Reynolds WN. Non-Hookean Behaviour of Strong Carbon Fibres. Nature. 1968; 220: 1024-5.

42. Lomov SV, Ivanov DS, Truong TC, et al. Experimental methodology of study of damage initiation and development in textile composites in uniaxial tensile test. Composites Science and Technology. 2008; 68: 2340-9.

43. Ivanov D, Ivanov S, Lomov S and Verpoest I. Strain mapping analysis of textile composites. Optics and Lasers in Engineering. 47: 360-70.

44. Daggumati S, Voet E, Paepegem WV, et al. Local Strain In A 5-Harness Satin Weave Composite Under Static Tension: Part I - Experimental Analysis. Composites Science and Technology. 2011; In Press, Accepted Manuscript.

45. Daggumati S, De Baere I, Van Paepegem W, et al. Local damage in a 5 - harness satin weave composite under static tension: part i - experimental analysis. Composites Science and Technology. In Press, Accepted Manuscript.

46. Mori $\mathrm{T}$ and Tanaka K. Average stress in matrix and average elastic energy of materials with misfitting inclusions. Acta Metallurgica. 1973; 21: 571-4.

47. Rattan R, Bijwe J and Fahim M. Optimization of weave of carbon fabric for best combination of strength and tribo-performance of polyetherimide composites in adhesive wear mode. Wear. 2008; 264: 96-105. 